Article

\title{
Bimetallic Substituted Ceria: An Alternative Approach to Ligand-Free Heck-Mizoroki Cross-Coupling Reactions
}

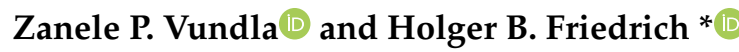 \\ School of Chemistry and Physics, University of KwaZulu-Natal, Durban 4000, South Africa; \\ zanele.p.vundla@gmail.com \\ * Correspondence: Friedric@ukzn.ac.za
}

Received: 29 May 2020; Accepted: 1 July 2020; Published: 16 July 2020

check for updates

\begin{abstract}
This work describes $\mathrm{Ce}_{0.89} \mathrm{Zr}_{0.03} \mathrm{Pd}_{0.08} \mathrm{O}_{2-\delta}$ as a heterogeneous catalyst for Heck-Mizoroki reactions. The material was synthesised by urea-assisted solution combustion to give a zirconium-stabilised cerium fluorite structure, with a fraction of palladium incorporated into the host structure. Characterisation techniques included ICP-OES, P-XRD and electron microscopy. The catalyst illustrated a high TOF of $1860 \mathrm{~h}^{-1}$ for the cross-coupling of iodobenzene with methyl acrylate, when trimethylamine (TEA) was used as a base and dimethylformamide (DMF) as the solvent at $130{ }^{\circ} \mathrm{C}$. To establish the activity of coupling pairs, screening was limited to aryliodobenzenes, with various electronic properties, to determine the influence of aryliodobenzene electronic density on the trans product yield. Electron-donating substituents showed good yields, while electron-withdrawing groups had lower yields. Furthermore, various classes of electron-deficient olefins were screened to determine any effect on the trans product yield. Electron-deficient olefins showed higher yields with regard to the trans product than neutral styrene.
\end{abstract}

Keywords: Heck reactions; cross-coupling; heterogeneous; catalyst; palladium; cerium; zirconium; leaching; substituted

\section{Introduction}

The Heck reactions involve the formation of a new carbon-carbon double bond connecting an aryl halide with an olefin. This process is referred to as the arylation of olefins, or the vinylation of aryl halides. Typically Heck reactions-as with many cross-coupling reactions-are palladium-catalysed [1]. Classically, homogenous catalyst systems are used in the industrial applications of Heck reactions [2-7]. Naturally, while homogenous systems have high turn-over frequencies (TOFs), their major disadvantage is the inability to be efficiently seperated from the final product. Incorporation of the catalyst in turn decreases the quality of the final product in terms of purity [5,6,8-13]. For pharmaceutical products, incorporation of the catalyst can be detrimental, but most notable is the economic consideration, since palladium is a precious metal and is thus expensive and offers limited recycling prospects as a homogenous catalyst $[5,14,15]$.

The most obvious approach to solving this problem is the employment of a heterogeneous system [6]. However, while this approach may work for many systems, heterogeneous catalyst systems under Heck conditions generally leach [6,15-18]. This is a process in which the active metal dissolves in solution and becomes homogenized into the reaction medium as with homogeneous systems $[1,14,15,19-21]$. Once more, the problems of the incorporation of precious metal and limited recyclability emerge. Thus, this paper attempts to develop a heterogeneous catalyst system, which is sufficiently active for Heck reactions, yet displays minimal or no leaching. 
Although a great variety of materials can be applied, the drawbacks of low turn over numbers (TONs) and turn over frequencies (TOFs) which the amount of product a catalyst can turn over per mol of catalyst ( and TOFs being TONs per unit time) are of great concern. Although the stability of catalysts has been improved by exploring ligand-free alternatives, these methodologies tend to complicate the synthesis procedure by requiring additives. The contribution by Mpungose of introducing quaternary ammonium salts, has illustrated excellent results under milder conditions [22]. Furthermore, the use of ammonium salts as phase transfer agents has been reported to also provide stability to the active metal [14]. This then introduces another facet to the heterogeneous catalyst debate, of whether a truly ligand-free catalyst is possible, since the active metal will coordinate to substrates, which then act as ligands. This limits the scope of substrates that can be employed by virtue of their ability to "ligate" and "dissociate".

Fortunately, immobilised homogenous systems, through covalent bonding, encapsulation and/or complexation, provide a more stable catalyst that can be recycled [5]. Furthermore, supported metal catalysts, where the active metal is on a solid support, have increased the palette of materials that can be applied [5]. These materials range from carbon supports, to zeolites, porous glass, clays, metal oxides, organic polymers, molecular sieves, and various combinations of the materials mentioned. These supports offer a myriad of advantages, such as stability (both thermal and to moisture), tuneable selectivity, and recyclability. These supports were introduced in the early 1970s, and this has left this field well studied $[8-13,19]$. The low TONs and TOFs of these materials have been a major disadvantage. These stable catalysts allow an increase in the operating temperature and pressure range that can be used to compensate for the activity, however, TONs are still incomparable to those of homogenous systems. Nevertheless, $\mathrm{Pd} / \mathrm{C}$ has been shown, in the work of Perosa in coupling reactions, to give TONs that are suitable for industrial applications [23]. Noteworthy is the apparent consequence of complete exclusion of homogeneous systems from heterogeneous systems comes in the form of an impractical loss in TONs, as illustrated in Table 1.

Table 1. Heterogeneous catalyst systems applied in Heck reactions with their TONs and TOFs.

\begin{tabular}{|c|c|c|c|c|}
\hline Entry & Catalyst & TON & TOF & Ref. \\
\hline 1 & $\begin{array}{l}\mathrm{Pd} / \text { functionalised } \\
\text { micro gels }\end{array}$ & 375 & 16 & [24] \\
\hline 2 & Pd/polymers & 12,375 & 138 & [25] \\
\hline 3 & $\mathrm{Pd} /$ dendrimers & 273 & 34 & [26] \\
\hline 4 & Pd/Chitosan & 8000 & 2000 & [27] \\
\hline 5 & Pd/MCM 41 & 23,333 & 5833 & [28] \\
\hline 6 & Pd/ETS-10 & 192,000 & 192,000 & [29] \\
\hline 7 & $\mathrm{Pd} / \mathrm{LDH}$ & 245 & 15 & [30] \\
\hline 8 & $\mathrm{Pd} /$ mordenite & 792 & 396 & [31] \\
\hline 9 & $\begin{array}{l}\mathrm{Pd} / \mathrm{HY} \text { or Beta } \\
\text { zeolite }\end{array}$ & 330 & 55 & [32] \\
\hline 10 & $\mathrm{Pd} /$ silica & 3300 & 550 & [33] \\
\hline 11 & Pd/Carbon & 2000 & 6667 & [23] \\
\hline
\end{tabular}

Hence, a different approach to homogeneous catalysts, to give reusable heterogeneous catalysts, has been initiated [19]. This different approach could combine the advantages of both homogeneous and heterogeneous catalysts. Such methods include a "ship in a bottle" catalyst concept. This notion sees the retention of a homogeneous catalyst system within zeolite pores [8-13]. The guest is retained in the zeolites because of sterical hindrance. Alternatively, impregnation of the active metal or compounds on a solid support can immobilise the active catalyst. Parallel to impregnation is the enhancement of physiosorption, via the choice of a porous material of suitable size for the compound to be deposited. However, these systems still suffer from leaching $[14,19]$. Additionally, the immobilisation of desired compounds by the formation of covalent bonds, which is known as grafting [8-13]. This can be done in the form of a linker, which increases the strength of the bond between the support and active compound 
or metal, theoretically minimsing leaching. The sol gel process can also b0e used, which involves the generation of a monomer with part of the active metal encapsulated.

Finally, the use of substituted materials or interstitials has been reported. The greatest feature of this method is the culmination of all the methodologies that have been discussed. The active metal is substituted at an atomic level in the crystal lattice of a host material. Theoretically, leaching should be reduced or eliminated. Furthermore, in the case of leaching, the active metal may leach and get redeposited into the pores of the host material, functioning as a supported material. Many reports claim a reversible "release-and-capture" process that occurs with such materials [14,34]. Therefore, great attention needs to be paid to the choice of host/support material. For instance, pores in zeolites are more tuneable than metal oxides, while metal oxides such as $\mathrm{CeO}_{2}$ have an ability to move through phases, and are able to change their oxidation state to release electronic strain, and are thus suited to application in substituted materials [8-13,35-38]. The susceptibility of ceria to changed oxidation states allows for various metals to be substituted into the fluorite structure; however, this phenomena may indeed be the reason for leaching.

This work describes the substitution of zirconium and palladium atoms into the cerium host structure [39-41], as illustrated in Figure 1. The use of palladium as the active metal was appealing since most cross-coupling reactions are palladium-catalysed; additionally, the use of a basic metal oxide in conjunction with the active metal has been proven to be effective [6].

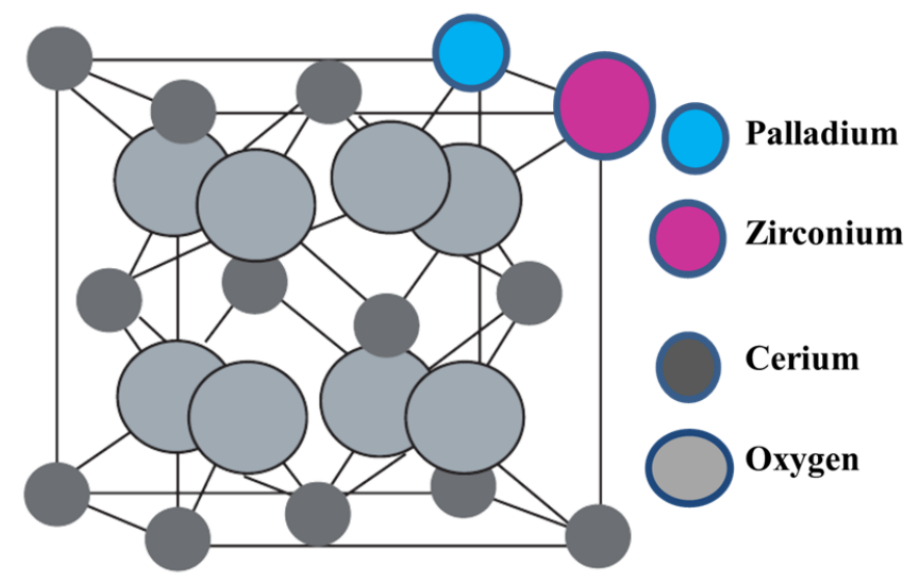

Figure 1. Illustration of substitution in the fluorite structure of cerium.

Typically, ceria can tolerate no more than $20 \%$ of zirconium atoms; thereafter, mixed phases arise [36,42-44]. Therefore, this work aimed to minimise leaching of the active metal by incorporating a fractional amount of palladium into a zirconium-stabilised ceria host lattice. While the reaction mechanisms of heterogeneous systems have been widely speculated about, the true active species is still not known, and consequently this work models reactions after a $\mathrm{Pd}^{2+}$ mechanism [45-49].

\section{Results}

Following the synthesis of the material with the $\mathrm{Pd}^{2+}$ ion encased in a ceria-zirconium solid solution, the metal loading was determined via ICP-OES, shown in Table 2.

Table 2. Metal loadings as determined from ICP-OES analysis.

\begin{tabular}{cccc}
\hline Catalysts & Pd Atom \% & Ceria Atom \% & Zirconia Atomic \% \\
\hline $\mathrm{Ce}_{1-(\mathrm{x}+\mathrm{y})} \mathrm{Zr}_{\mathrm{x}} \mathrm{Pd}_{\mathrm{y}} \mathrm{O}_{2-\delta}$ & 8 & 89 & 3 \\
$\mathrm{Pd} / \mathrm{Ce}_{1-\mathrm{x}} \mathrm{Zr}_{\mathrm{x}} \mathrm{O}_{2-\delta}$ & 7 & 90 & 3 \\
$\mathrm{Ce}_{1-\mathrm{x}} \mathrm{Zr}_{\mathrm{x}} \mathrm{O}_{2-\delta}$ & 0 & 97 & 3 \\
\hline
\end{tabular}


Imperative to this study was the incorporation of Pd in the cerium-zirconium lattice; therefore, a relatively high $\mathrm{Pd}$ loading was used to establish the affinity of $\mathrm{Pd}$ to the cerium-zirconium lattice. Surface Pd deposits from unsuccessful incorporation can easily be identified by P-XRD. Fortunately, where solid solution is concerned, preservation of the structural integrity of the cubic cerium lattice is only possible for dopants with below $20 \%$ of atoms before mixed phases arise [36,42-44]. In accordance with the Hume Rothery rules of substitution [50], the percentage difference in the atomic radii of $\mathrm{Pd}^{2+}$ and $\mathrm{Ce}^{4+}$ is far smaller than that of $\mathrm{Zr}^{4+}$, thus the addition of $\mathrm{Pd}^{2+}$ is likely to introduce more defects in the host structure. A STEM Energy Dispersion X-ray spectroscopy (STEM-EDX) line scan was done on the $\mathrm{Ce}_{0.89} \mathrm{Zr}_{0.03} \mathrm{Pd}_{0.08} \mathrm{O}_{2-\delta}$, as shown in Figure 2 .

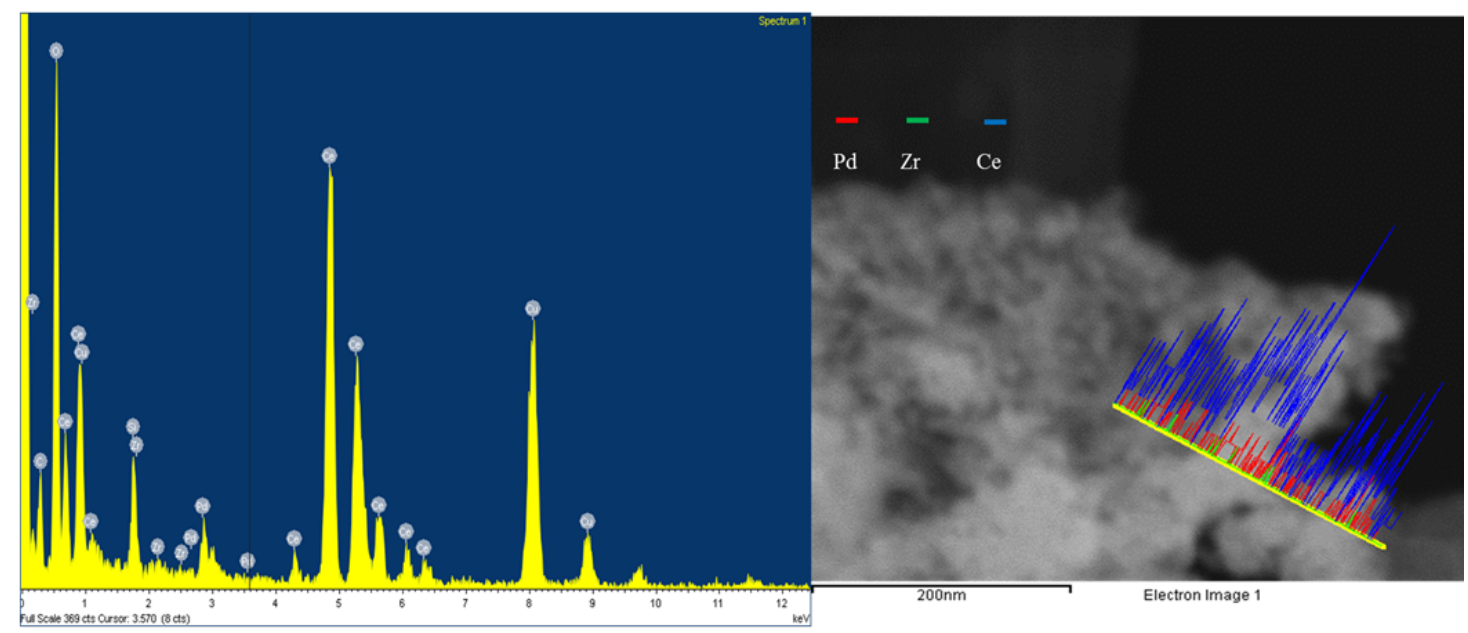

Figure 2. STEM-EDX spectrum with elemental compositions line scan of $\mathrm{Ce}_{1-(\mathrm{x}+\mathrm{y})} \mathrm{Zr}_{\mathrm{x}} \mathrm{Pd}_{\mathrm{y}} \mathrm{O}_{2-\delta}$.

This illustrates the abundance of elements in the sample across the selected area, marked by the yellow line, and the distribution of $\mathrm{Ce}, \mathrm{Pd}$ and $\mathrm{Zr}$. The line scan is characterised by a high Ce content throughout the area of interest, with sparse amounts of $\mathrm{Zr}$. The Pd is uniformly dispersed with a constant intensity throughout the line scan. A line scan showing localised regions of metal distribution would be indicative of surface metal deposits. On a qualitative basis, the spectrum illustrates the abundance of the respective metals in ratios relatively consistent with those determined by ICP-OES. Figure 3 illustrates the $\mathrm{X}$-ray diffractograms of (a) $\mathrm{CeO}_{2}$, (b) $\mathrm{Ce}_{0.97} \mathrm{Zr}_{0.03} \mathrm{O}_{2-\delta}$, (c) $\mathrm{Ce}_{0.89} \mathrm{Zr}_{0.03} \mathrm{Pd}_{0.08} \mathrm{O}_{2-\delta}$ and (d) $\mathrm{Pd} / \mathrm{Ce}_{0.97} \mathrm{Zr}_{0.03} \mathrm{O}_{2-\delta}$, with the reflective planes indexed. Each pattern shows the dominant face-centred cubic (fcc) pattern of ceria between the 2-theta values of $27^{\circ}$ and $80^{\circ}$, consistent with the JCPDS card (81-0792) [37,51,52] belonging to the Fm3m space group, and no additional peaks from tetragonal zirconia and $\mathrm{PdO}$, implying the complete incorporation of both $\mathrm{Zr}$ and $\mathrm{Pd}$ into the fluorite native structure [51-54]. The exception is the diffractogram at (d), the material intended to have $\mathrm{Pd}$ surface deposits, which shows surface Pd-O as a shoulder at 2-theta $=31^{\circ}$ [51]. Therefore, surface deposits of palladium show an additional phase manifesting as a shoulder in the 200 reflection plane of cerium oxide. 

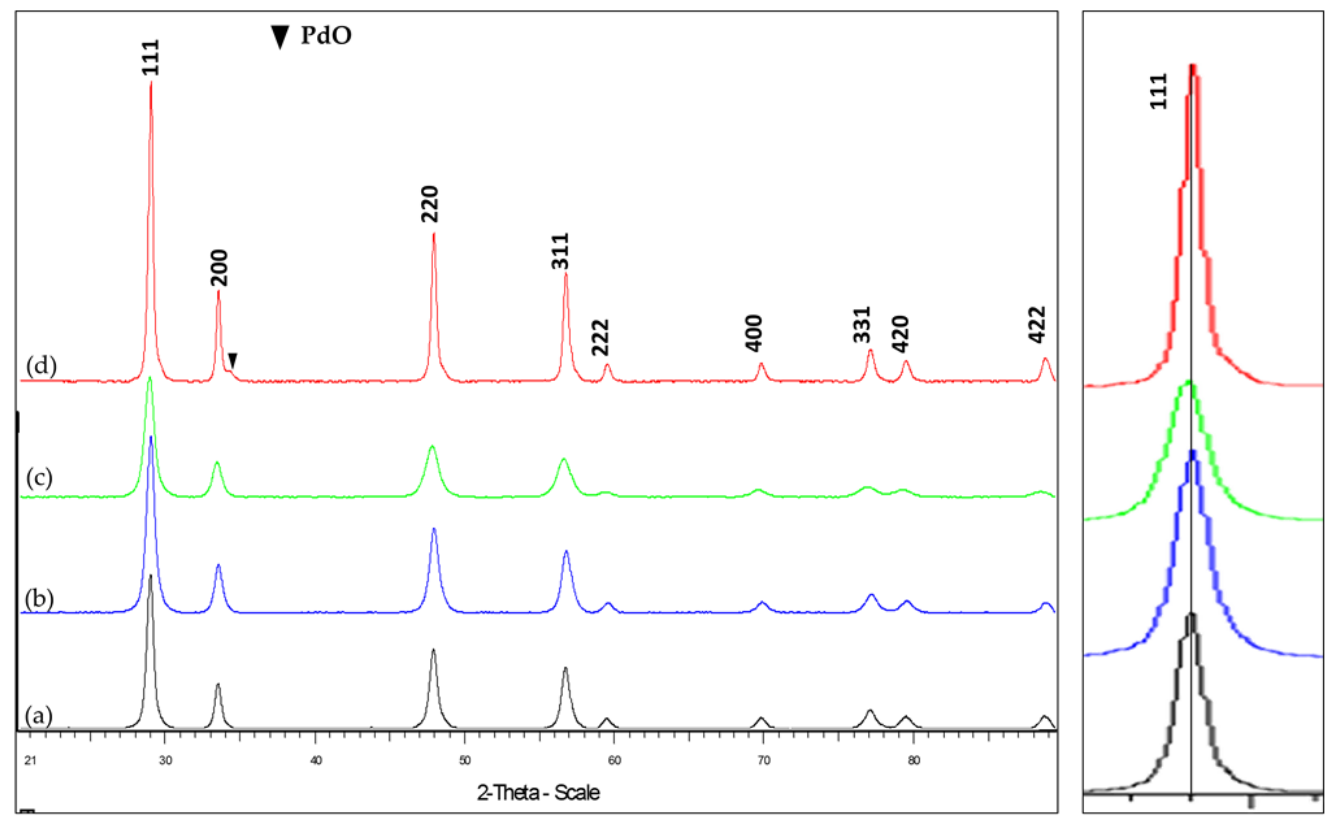

Figure 3. X-ray diffractograms of (a) $\mathrm{CeO}_{2}$, (b) $\mathrm{Ce}_{0.97} \mathrm{Zr}_{0.03} \mathrm{O}_{2-\delta}$, (c) $\mathrm{Ce}_{0.87} \mathrm{Zr}_{0.03} \mathrm{Pd}_{0.08} \mathrm{O}_{2-\delta}$ and (d) $\mathrm{Pd} / \mathrm{Ce}_{0.97} \mathrm{Zr}_{0.03} \mathrm{O}_{2-\delta}$ with the magnified region at $29^{\circ}$ 2-theta.

Additional data from the diffractograms, namely d-spacings, crystallites sizes and average lattice strain values calculated from the Williamson-Hall plot, are listed in Table 3. The addition of Zr into the cerium lattice leads to no change in the overall strain observed or the strain averages. This is because $\mathrm{Zr}$ is of a similar size, valency and electronegativity as the Ce and thus does not appear as a "foreign" atom in the host structure. Palladium has a lower solubility due to the difference in size and electronegativity. However, metals with higher valencies can dissolve metals with lower valency, as is the case here with cerium and palladium [55]. This then translates to lower electrostatic repulsion between $\mathrm{Ce}$ and $\mathrm{Pd}$, which thus decreases strain.

Table 3. $\mathrm{d}$-spacing and strain calculations of the respective materials.

\begin{tabular}{|c|c|c|c|c|}
\hline Catalyst & Crystallite Size (nm) & Strain & d-Spacing (Å) & a $(\AA)$ \\
\hline $\mathrm{CeO}_{2}$ & 10.71 & 0.0053 & 3.08776 & 5.22321 \\
\hline $\mathrm{Ce}_{0.97} \mathrm{Zr}_{0.03} \mathrm{O}_{2-\delta}$ & 17.97 & 0.0053 & 3.08450 & 5.21773 \\
\hline $\mathrm{Pd} / \mathrm{Ce}_{0.97} \mathrm{Zr}_{0.03} \mathrm{O}_{2-\delta}$ & 20.40 & 0.0050 & 3.08397 & 5.21826 \\
\hline $\mathrm{Ce}_{0.89} \mathrm{Zr}_{0.03} \mathrm{Pd}_{0.08} \mathrm{O}_{2-\delta}$ & 14.66 & 0.0013 & 3.09208 & 5.23048 \\
\hline
\end{tabular}

The larger crystallite size of the cerium-zirconium solid solution resulted from the presence of the oxygen vacancies that formed, which cause the interplanar distances to decrease [54]. However, when palladium is incorporated into the ceria-zirconia solid solution through solution combustion, instead of depositing onto the surface, the palladium resides in the vacancies of the solid solution. As a result of filling the vacancies with palladium atoms, ionic repulsion is decreased, making the overall crystallite size smaller than that of the ceria-zirconia solid solution [43,44,53]. This phenomena was also observed by Gulyaev [38], where the addition of palladium resulted in strain relief given the low valency of palladium, which decreased electrostatic repulsion in the host lattice [54]. Furthermore, Gulyvaev attributed the increase in d-spacings to the increase in defects, which were caused by the addition of the Pd ions in the ceria-zirconia solid solution in an attempt to relieve strain in the lattice [38]. Thus, an increase in the interplanar spacings was observed, as in this work, and with the incorporation of the smaller Pd atom it is observed that the crystallite size decreases, while the edge lengths of the fcc lattice increase. 
The representative TEM image from the particle size analysis of $\mathrm{Ce}_{0.89} \mathrm{Zr}_{0.03} \mathrm{Pd}_{0.08} \mathrm{O}_{2-\delta}$ is shown in Figure $4 \mathrm{a}$, showing spherical particles with distinctive grain boundaries and an average grain size of 7.73 $\mathrm{nm}$, with a low standard deviation of $\pm 0.69 \mathrm{~nm}$, indicating the uniform size of the material $[38,52,56]$. The inter-planar spacing values of $3.0 \AA, 2.6 \AA$ and $2.0 \AA$, measured from the HRTEM images in Figure 4a, were correspondingly assigned to the (111), (200) and (220) planes of the fluorite structure of cerium oxide, indicating substitution $[38,52]$.
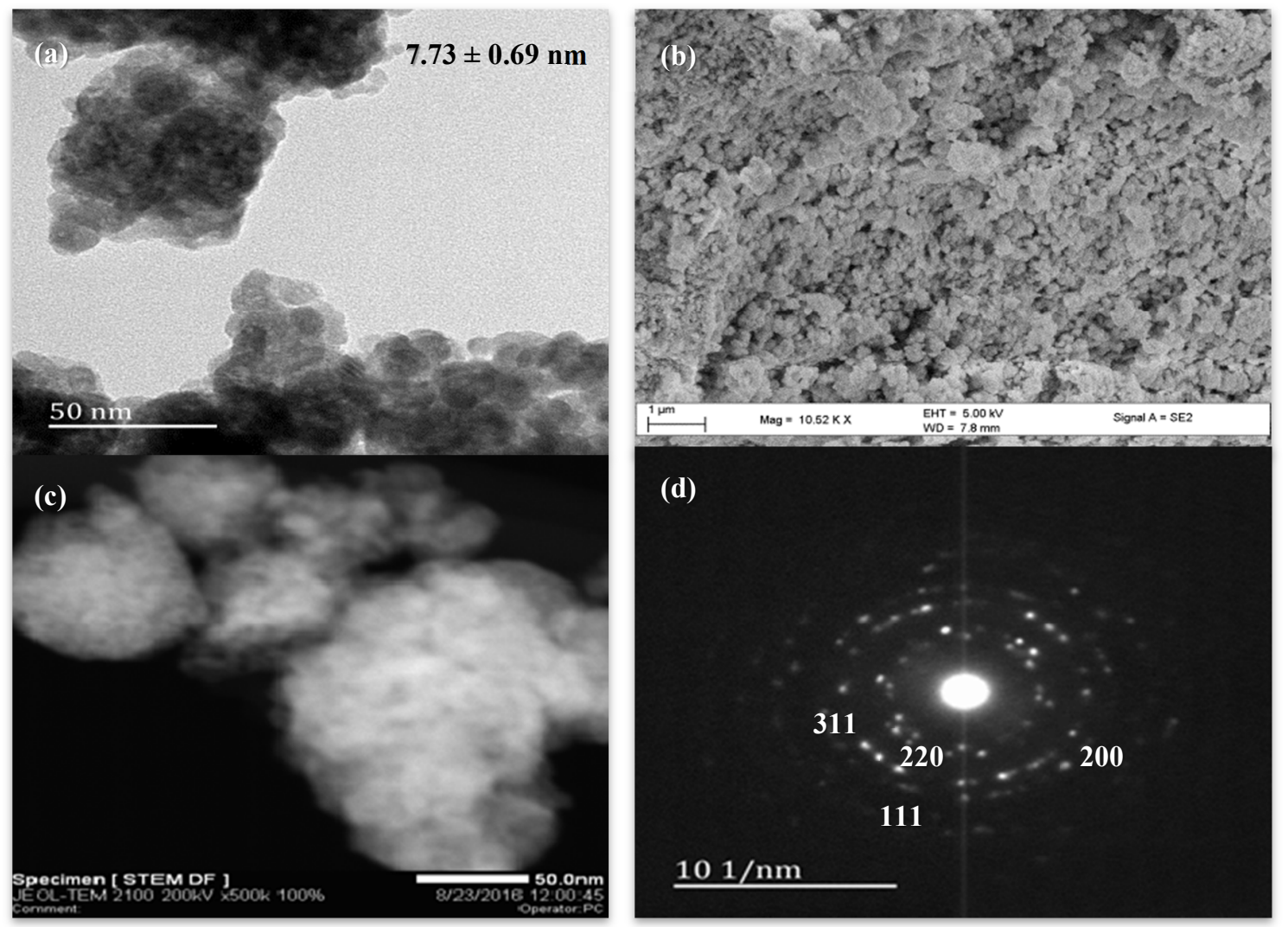

Figure 4. Microscopic analysis of $\mathrm{Ce}_{0.089} \mathrm{Zr}_{0.03} \mathrm{Pd}_{0.08} \mathrm{O}_{2-\delta}$; (a) HRTEM image, (b) SEM micrograph, (c) STEM-DF image, and (d) Poly crystalline electron diffraction pattern.

The contrast in the image is uniform, without dense regions that would indicate palladium nanoparticles on the surface of the cerium-zirconium solid solution. The surface morphology illustrated by the SEM micrograph also shows spheres of variable sizes, suggesting sintering of the material, and thus the surface area of the material is expected to be low. Furthermore, the material also shows hollow regions that indicate large pore diameters. The Scanning Electron Microscope-Dark Field (STEM-DF) image (Figure 4c) shows a material of uniform brightness, while bright localised regions would indicate surface metal deposits. The geometry of the diffraction pattern of Figure $4 \mathrm{~d}$ relates to the [011] zone axis [36,57]. The electron diffraction pattern, from previous reports of the fcc structure, is characterised by electron diffraction rings with interplanar spacings corresponding to ca. $3.1 \AA$, related to the 111 reflection plane, $2.7 \AA$ related to the 200 reflection plane, and $1.9 \AA$ related to the 220 reflection plane [36,57]. With the presence of other phases, such as the tetragonal phases of $\mathrm{PdO}$ and $\mathrm{ZrO}_{2}$, additional reflections would be observed. Reports of cerium-zirconium solid-solutions describe a single cubic phase for substitutions below $20 \%$, before monoclinic and tetragonal phases become apparent $[42,43,53]$. Thus, the fcc structure of cerium oxide is confirmed.

The optimum reaction conditions were determined and listed in Table 4, with screening solvents, bases and temperatures, using the reaction between iodobenzene and methylacrylate as the standard reaction. All conversions exceeded 99\%. 
Table 4. Results of the optimisation reactions between iodobenze and methylacrylate.

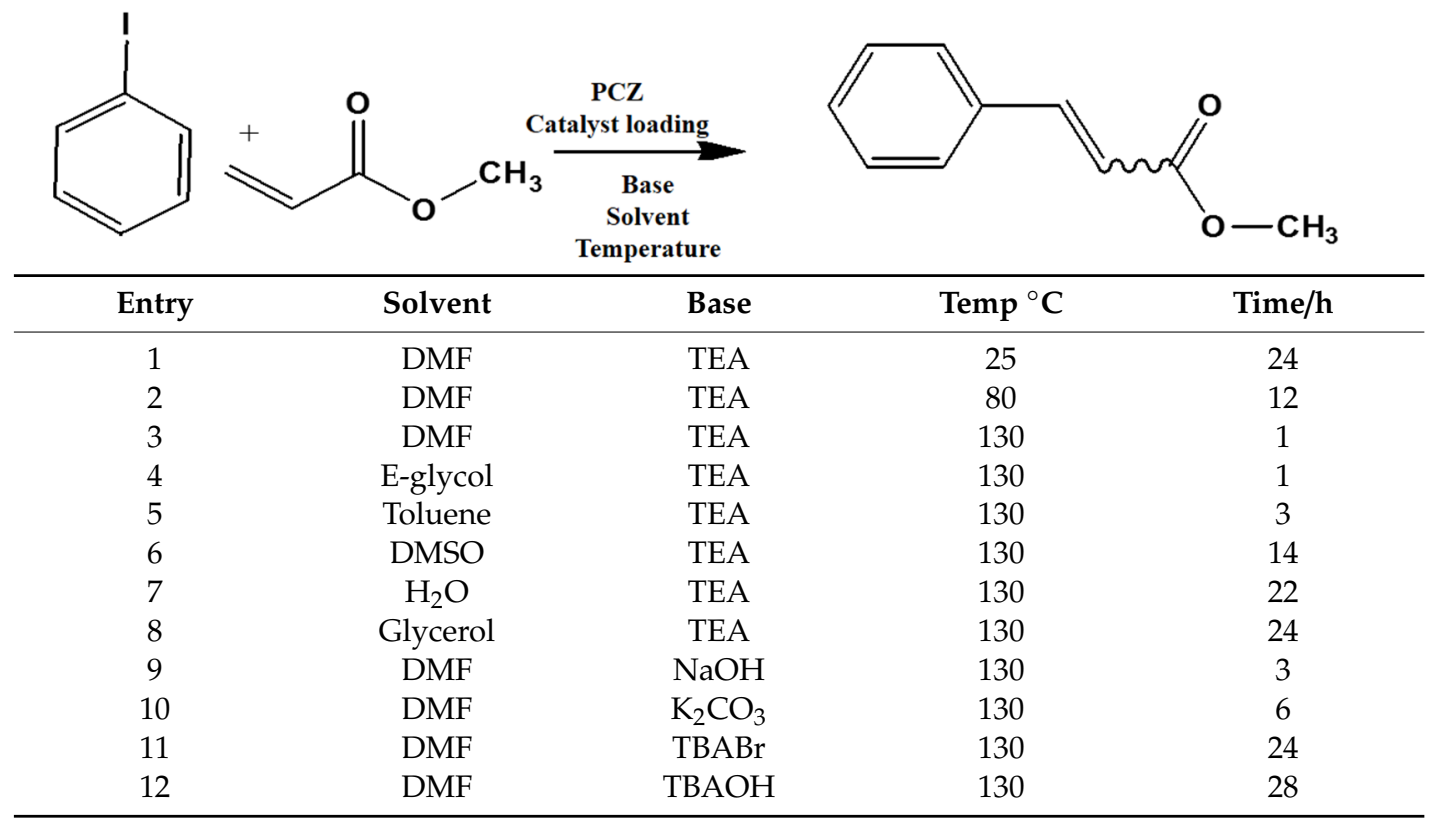

DMF $=$ Dimethyl formamide, TEA = Triethylamine, E-glycol $=$ Ethylene glycol, DMSO $=$ Dimethylsulfoxide, $\mathrm{H}_{2} \mathrm{O}=$ water, $\mathrm{NaOH}=$ Sodium hydroxide, $\mathrm{K}_{2} \mathrm{CO}_{3}=$ Pottasium carbonate, $\mathrm{TBABr}=$ Tetrabutylammonium bromide, $\mathrm{TBAOH}=$ Tetrabutylammonium hydroxide.

The optimum temperature for this system was found to be $130^{\circ} \mathrm{C}$. Although complete conversion is possible at room temperature, the higher the temperature, the shorter the reaction times required $[5,58]$. Thus, the reaction time at $25^{\circ} \mathrm{C}$ was $24 \mathrm{~h}$, at $80^{\circ} \mathrm{C}$ the reaction time was halved to $12 \mathrm{~h}$, while a $1 \mathrm{~h}$ reaction time was observed at $130^{\circ} \mathrm{C}$, when DMF was used as a solvent and TEA was used as a base. With respect to solvents, polar aprotic solvents have been reported as the ideal solvents for Heck reactions [5], hence the $1 \mathrm{~h}$ reaction time observed for DMF. In contrast, the polar aprotic DMSO showed longer reaction times compared to DMF [5]. This is because, in addition to DMF being aprotic, this solvent also has a coordinating ability and acts a ligand which stabilises the catalyst-base intermediate, which is formed in the pre-activation step and influences the migratory insertion pathway $[59,60]$. Typically, the challenge with the use of protic solvents is their labile nature, due to their acidic protons. The protons make the reaction media acidic, resulting in the decomposition of the organopalladium complex formed by oxidative addition [60], hence the necessity of adding a base. Ethylene glycol and water, on the other hand, have poor miscibility with the substrates, resulting in a biphasic system, leading to the partitioning of the substrates between the two phases, making sampling dependent on the partitioning coefficient of the cross-coupled product between the two solvent mediums. Additionally, the use of water resulted in a longer reaction time of $22 \mathrm{~h}$. With respect to the use of non-polar solvents, these solvents do not coordinate to the catalyst, which is important for the stability of intermediates that is usually provided by the ligands in organometallic catalysts, as well as regioselectivity. Thus, while toluene gives a shorter reaction time, non-polar solvents favour insertion at the $\beta$ carbon, decreasing selectivity to the trans product [61]. Finally, with respect to the base selection, triethylamine gave a reaction time of $1 \mathrm{~h}$. Although the strong base $\mathrm{NaOH}$ was effective, because alkenes are stable under basic conditions, esters are susceptible to hydrolysis in the presence of a strong base. Once hydrolysis occurs on the ester "segment" of an acrylate to form a carboxylic acid, this new substrate will have a different reactivity to cross-coupling reactions, hence the long reaction times when $\mathrm{NaOH}$ was used. Oxidative cross-coupling is typically observed when $\mathrm{NaOH}$ is used [62].

Stoichiometric amounts of tetraammonium salts are additives that have been reported to improve reaction times when used in conjunction with an inorganic base [22]. However, the use of tetrabutylammonium bromide or tetrabutylammonium hydroxide as a base rather than an additive 
resulted in reaction times of $24 \mathrm{~h}$ and $28 \mathrm{~h}$, respectively. Substantially longer reaction times $(6 \mathrm{~h})$ compared to triethylamine ( $1 \mathrm{~h}$ ) were found when using the inorganic base $\mathrm{K}_{2} \mathrm{CO}_{3}$ [63].

Catalyst loading was then investigated to determine the minimum loading required to achieve $>99 \%$ conversion in $1 \mathrm{~h}$. Employing the optimum reaction conditions, based on the base, solvent and temperature investigations, various loadings of catalyst were then explored. The base used was triethylamine with DMF as a solvent, at $130^{\circ} \mathrm{C}$. Figure 5 shows the reaction profile of the various catalyst loadings studied at 10-min reaction intervals.

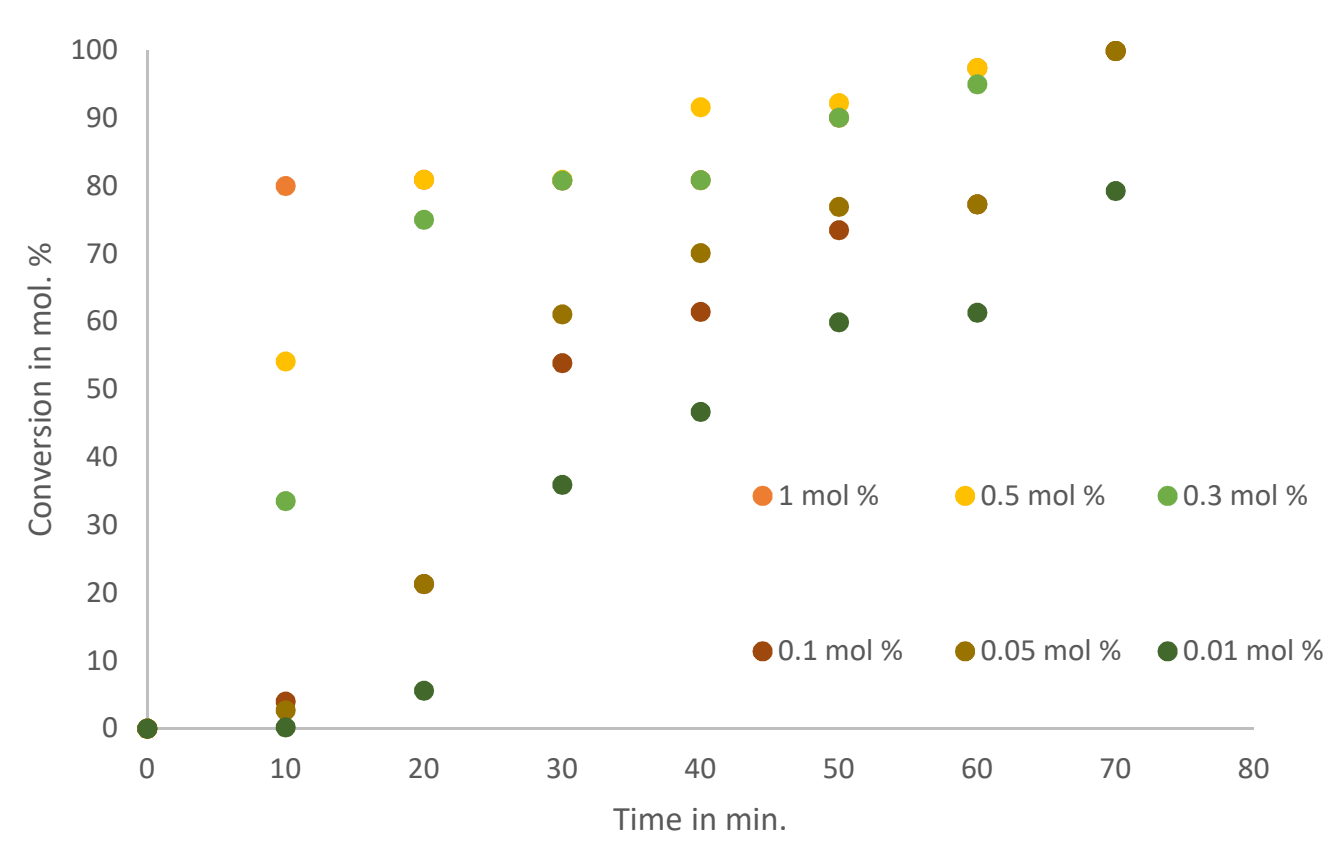

Figure 5. Reaction profiles at 10-minute intervals of the catalytic reactions with various loadings of Pd.

The catalyst was found to be very active at loadings as low as $0.05 \mathrm{~mol} \%$ of Pd ( $>99 \%$ in $75 \mathrm{~min}$ ), while a loading of $0.01 \mathrm{~mol} \%$ of $\mathrm{Pd}$ was less effective, since these reactions required $12 \mathrm{~h}$ to reach completion. The general activity of the catalysts with $\mathrm{Pd}$ loadings between 0.05 and $1 \mathrm{~mol} \%$ is characterised by a sharp gradient in the first 10 minutes, and then the rate of reaction slows down with the depletion of the substrate. While the $0.01 \mathrm{~mol} \%$ Pd-loaded catalyst displays an induction period, likely due to the transformation of the catalyst to the "true" catalyst [64,65], at higher loadings this induction period is not observed, likely due to the rate of reaction. Therefore, testing for the Heck activity of the catalyst was limited to the use of iodobenzene with various substituents to control electron density, and the conditions were set at $0.05 \mathrm{~mol} \% \mathrm{Pd}$ in DMF and $1.5 \mathrm{~mol}$ equivalence triethylamine at $130{ }^{\circ} \mathrm{C}$.

Several electron-donating or electron-withdrawing aryl iodides afforded cross-coupling products with excellent yields. Of interest is the activity of the catalyst in the presence of substrates of varying electronics and sterical hindrance. To establish the optimal conditions with respect to the electronic contributions of coupling partners, substituents on the iodobenzene were changed based on their electronic strength, while keeping the olefin constant. Thereafter, olefins were varied based on their functional groups. Table 5 lists the TOFs obtained when aryl iodides of various electronics were reacted with methylacrylate. Establishing coupling pairs based on electron density, coupling reactions can then be predicted based on substrate type for this catalyst. Although regioselectivity in these reactions was controlled by the electron-withdrawing substrates, stereoselectivity is reversible and results from the torsal strain experienced by the product; therefore, a minor cis configuration product is observed. Product yield was calculated based on the ${ }^{1} \mathrm{H}-\mathrm{NMR}$ of isolated yields, observing the ratio of the cis and trans peaks in the mixture. 
Table 5. Influence of para-substituents on yield and progression of reactions.

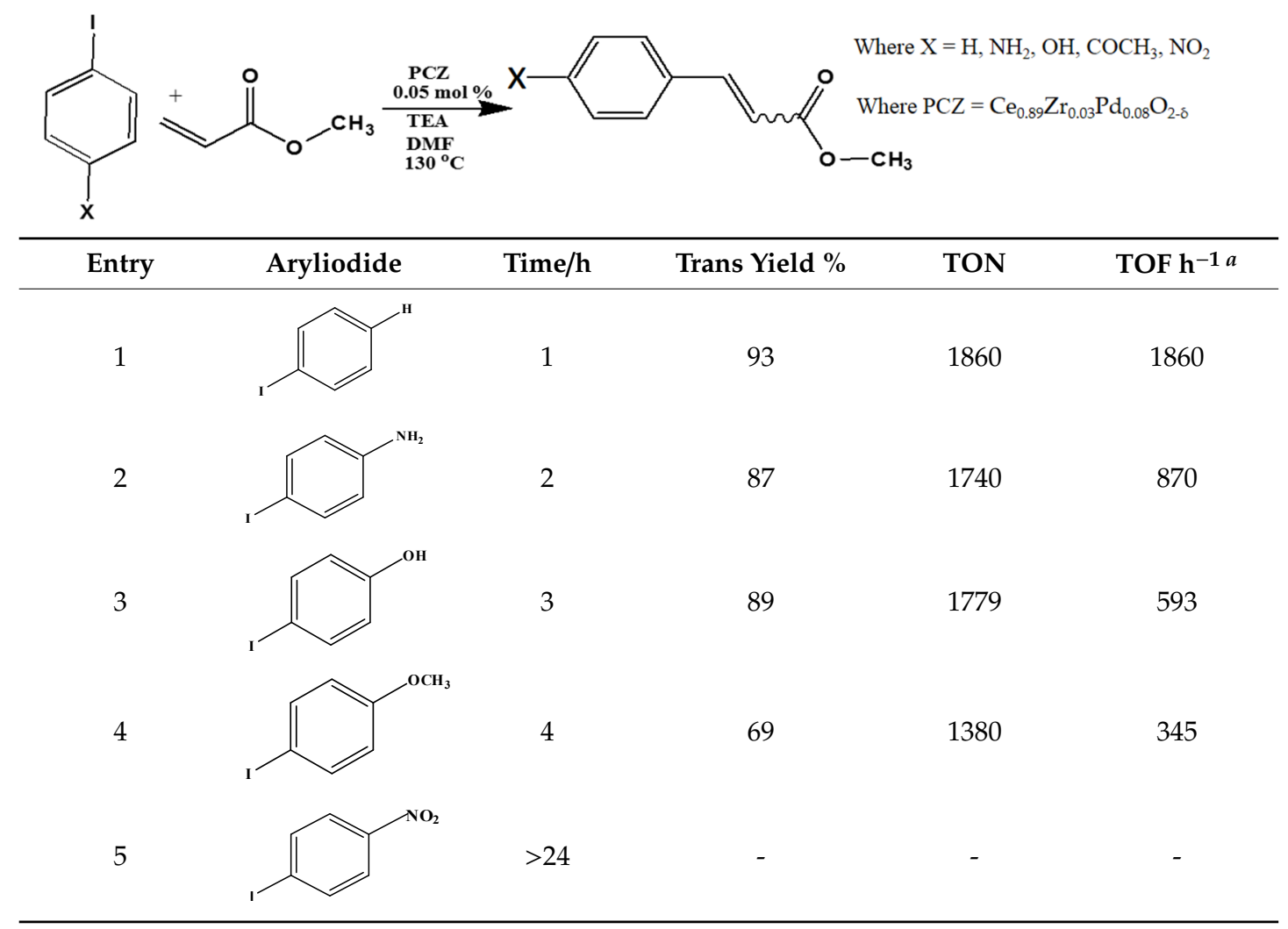

${ }^{a}$ Towards the trans product.

Entries 1-5 in Table 5 show the reaction of methyl acrylate, with substituted iodobenzenes with varying substituents in the para position, with methyl acrylate, which is moderately electron-withdrawing and has generally been used as a model reaction because of its high reactivity. Table 5 lists the yields, TONs and turn over frequencies TOFs at the $>99 \%$ conversion of iodobenzene, exclusively for the trans product yield.

The addition of an electron-donating substituents to the aryl halide results in polarisation of the C-X bond, making the C-X bond more reactive and thus susceptible to oxidative addition $[61,66,67]$, hence the trend in the reaction time observed from entries 1-5. From entries 2 and 3, the substituent begins to withdraw electrons more strongly, relative to entry $1(\mathrm{H})$. As a result, bond-polarisation decreases and the $\mathrm{C}-\mathrm{X}$ bond is less reactive, resulting in longer reaction times. Iodobenzene with the nitro group in the para position (entry 5) is strongly deactivated because of the high electron-withdrawing potential of the $\mathrm{NO}_{2}$ competing with the I group for electrons, which thus strengthens the C-I bond and decreases the reactivity. This explains the longer reaction times observed for the substrates with more electron-withdrawing groups.

However, the lower trans yields observed for iodobenzene with electron-withdrawing groups is due to their susceptibility to undergo homocoupling, where the aryl halide preferentially couples with itself $[61,68,69]$. Therefore, the reaction shows a fast depletion of the iodobenzene, but without giving the desired product. Consequently, as a result of the low concentration of the aryl halide in solution, free olefin decomposes over longer reaction times. Most notable is the reaction shown in entry 5 , with the nitro substituent para to the halide, with the reaction time exceeding $24 \mathrm{~h}$ but yielding no product. This was expected because, while $\mathrm{NH}_{2}, \mathrm{OH}$ and $\mathrm{OCH}_{3}$ withdraw electrons, they also donate electrons by resonance. Conversely, the $\mathrm{NO}_{2}$ is strongly deactivating. However, when the position of the nitro substituent was changed from para to meta, reaction times were observed to decrease. Table 6 shows the change in reaction and trans product selectivity under the stated reaction conditions and catalyst loading. 
Table 6. Influence of olefin electronics on the yield and progression of reactions.

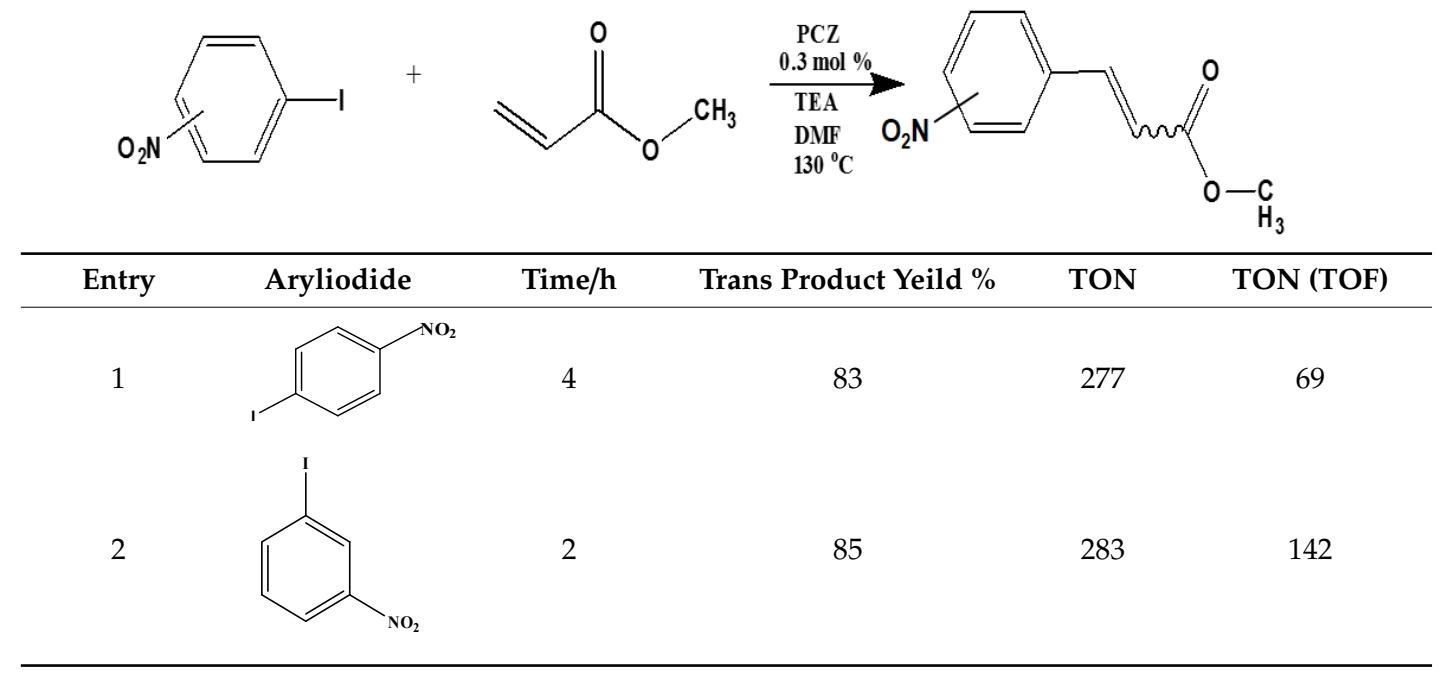

TON (TOFs) reported to trans product.

The reaction times observed show a significant decrease, but without significant change in trans yield. This suggests the electron-donating potential of the $m$-nitro-iodobenzene group, resulting in a decrease in reaction time by a factor of two compared to the more withdrawing $p$-nitro-iodobenzene group. Therefore, the positions of the substituents of the aryl halide are responsible for activating or deactivating the $\mathrm{C}$-I bond for oxidative addition. The $m$-nitro-group contributes to electron density by resonance, resulting in a more activated substrate.

It is, however, premature to assign priority to the electronics of the halide as the rate-determining step, since the influence of the olefin is still to be investigated, and migratory insertion is also an important step in the mechanism. For this investigation, Table 7 lists the substrates tested under the specified reaction conditions, where the electron density's contribution to the alkene is investigated, since that is where coupling occurs.

Table 7. Influence of olefin electronics on the yield and progression of reactions.

Fntry


Table 7, entries 1-4 are arranged from least reactive electron pairs to most reactive. This catalyst system shows high trans yields and short reaction times for electron-deficient olefins [69]. This is clearly seen in the reaction with the neutral styrene, where both reaction time and product selectivity are compromised. Secondary coupling due to the tendency of styrene to polymerise is typically found with stilbene (the styrene and iodobenzene coupling product), and this manifests in an apparent decrease in product yield. Initially, the desired product forms, and it then cross-couples further with styrene in a competing reaction. Entries 2 and 3 are for the reactions of methyl acrylate and acrylamide, which are electron-deficient; the trend seems to be that the more electron-deficient the molecule, the more susceptible it is to migratory insertion. Additionally, the preference for the trans isomer increases with the more electron-deficient substrates. Furthermore, the absence of branched products could be attributed to the steric hindrance on the alpha carbon, as well polarisation on the beta carbon due to the electron-withdrawing potential of the substituent on the alkene.

To investigate the effect of sterical hindrance on the double bond, Table 8 lists the acrylates that were used for this investigation with iodobenzene. Acrylates consist of an alkene segment, where cross-coupling occurs, and an ester segment. Therefore, two positions can be investigated, namely, the region around the alkene segment on the terminal carbon, as well as the ester segment of the molecule. However, cross-coupling is only concerned with the alkene segment. Considering the classical $\mathrm{Pd}^{2+}$ Heck mechanism approach, which assumes the migratory insertion of the terminal carbons, it then follows that the addition of a methyl group on the alkene segment should limit the progress of the reaction more so than the addition of a methyl group on the ester segment of the acrylate [60]. Furthermore, since cross-coupling is largely concerned with the alkene segment, because that is the centre of cross-coupling, steric hindrance at the ester segment should be negligible. Reaction times, as expected, increase significantly with the addition of a methyl group around the alkene segment. Table 8 summarises the results of the steric investigations.

Table 8. Investigation of steric hindrance about the double bond of the olefin.

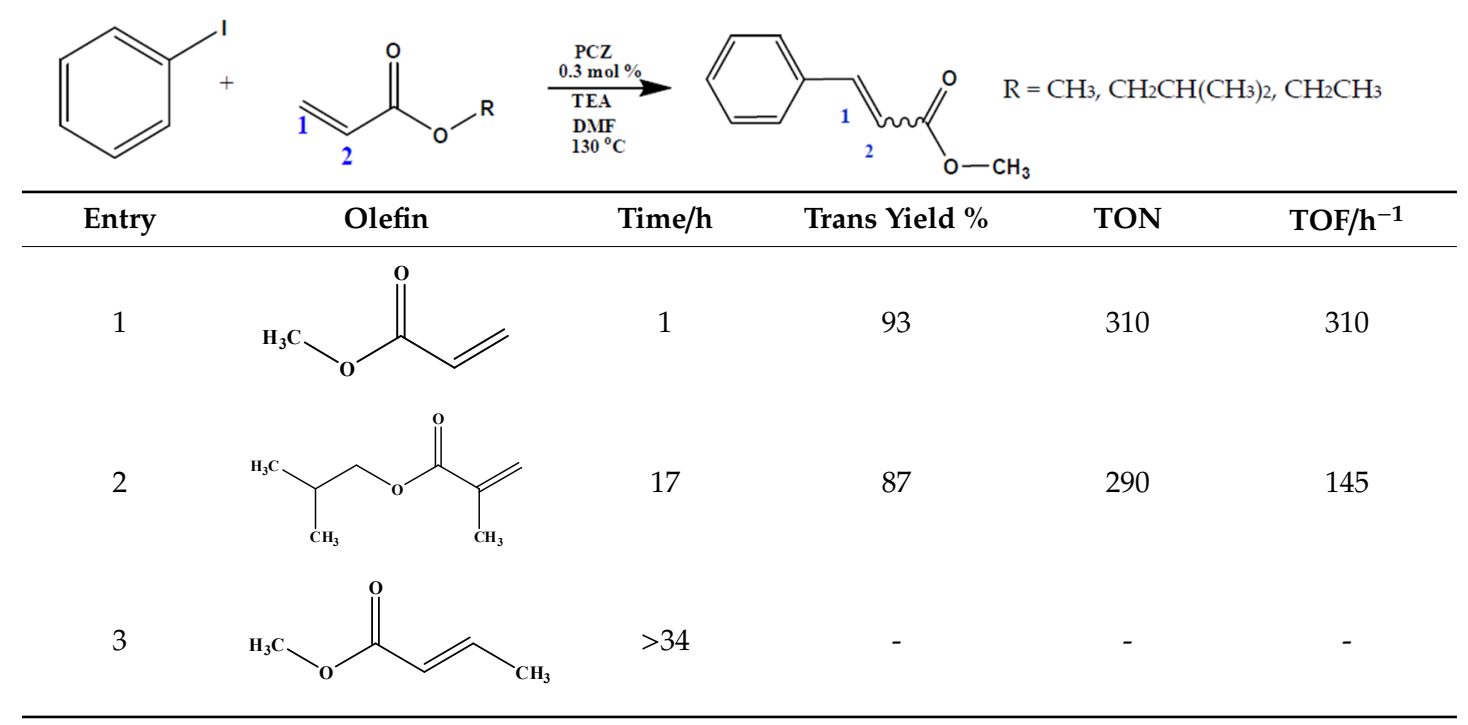

Entry 1 shows a short reaction time with a good yield where the double bond is not hindered. Surprisingly, for entry 2, where the carbon labelled 2 is hindered, reaction times increase significantly. However, reaction times greater than $34 \mathrm{~h}$ are observed when the terminal carbon is hindered, resulting in an olefin that is reluctant to cross-couple. This is because the double bond is completely hindered, while in entry 2 the isobutyl methacrylate still has the terminal carbon available for insertion. Therefore, steric hindrance is only a factor if the region around the double bond is substituted [60]. Additionally, the reactions described in Table 6 are attributed to the electron density endowed upon the double bond. To gain further understanding of the influence of electron density, both olefin and aryliodobenzenes 
were varied. Table 9 outlines the reaction parameters and substrates used. This was to establish the substrate scope. As it stands, electron-rich iodobenzenes with electron-poor olefins seem ideal for this catalyst system. For these reactions, only the TOFs and TONs were considered, as shown in Table 9, which gives a summary of the influence of olefins and halides on the extent of the reaction and linear trans product selectivity, reported as TONs and TOFs.

Table 9. Reactions between coupling pairs.

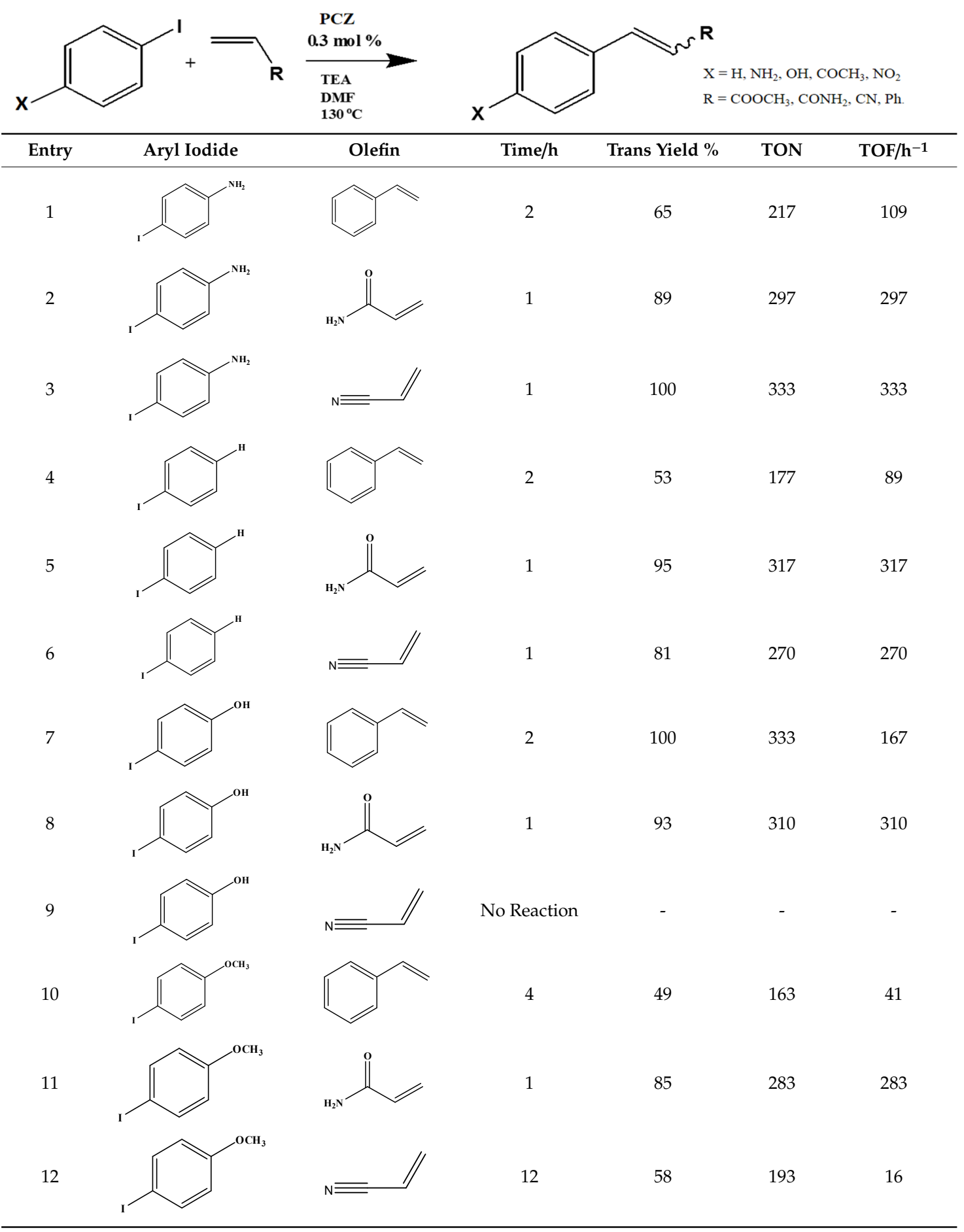


It is important to note the various stages at which each substrates is involved in the reaction, in order to better understand the relationships observed. Aryl halides are involved in the oxidative addition step that is governed by the reactivity of the $\mathrm{C}-\mathrm{X}$ bond $[59,70,71]$. Thus, an electron-withdrawing group should decrease the reactivity of the $\mathrm{C}-\mathrm{X}$ bond, increasing the rate of the oxidation step, since the $\mathrm{C}-\mathrm{X}$ bond does not get polarised, as is the case for the electron-donating substrates. Considering the reactions of methylacrylate with the various substituents, the reactions reach completion in $1 \mathrm{~h}$, with the exception of the reaction with the strongly withdrawing acetophenone, which completed in $2 \mathrm{~h}$. The TONs, however, are lowest for the electron-donating iodoaniline, and highest for the neutral iodobenzene. Substituents with electron-withdrawing groups in this case showed the lowest TOFs, as oxidative addition occurs much slower, as seen in Table 5, because the substituents are meta-directing. Additionally, yields for the desired product are low because of homocoupling typical of electron-withdrawing substrates.

On the other hand, olefins are involved in the reaction cycle at the migratory insertion step. However, this work focuses on the trans product yield, which requires regioselectivity control, and which is determined by the choice of olefin, hence the use of electron-deficient substrates [59]. Stereoselectivity is an irreversible kinetic phenomenon, and is determined in the syn elimination step. Pre-isomerisation may occur as soon as the olefin is introduced into the reaction media; secondly, it may occur once it is coordinated to the Pd-H centre, and finally, isomerisation may also occur when the cross-coupled product has formed [66]. However, stereoselectivity management is beyond the scope of this work. Noteworthy was the low trans yield observed for the reactions with styrene as the olefin [58]. The reaction resulted in a myriad of products, including the desired trans isomer, as well as homocoupling products characterised by an increase in the product peak given the absence of depletion of the aryly halide. Furthermore, considering the reactions of unsubstituted iodobenzene with the olefins of variable electron densities, reactions with a high, strongly electron-deficient acrylonitrile gave the best TOFs [72]. However, selectivity was low due to the size of the substituent. Methyl acrylate is more bulky, and thus the cis isomer is not favoured [73]. Most notable was the absence of the reaction between acrylonitrile and iodophenol; despite the substrates satisfying all the parameters discussed in this work, no reaction was observed. In this case, the iodide is cleaved faster than the rate at which the migratory insertion step can insert the acrylonitrile. After $1 \mathrm{~h}$ reaction time all the idodophenol is cleaved, forming phenols in solution that cannot react any further, and the desired reaction is not accomplished.

To investigate the extent to which the catalyst can be reused, recyclability tests were carried out. In this work, the catalyst was recycled three times, meaning that it was used in four consecutive reactions. Figure 6 shows the result using the optimum reaction condition when DMF is used as a solvent, with trimethylamine as the base and with a $0.3 \mathrm{~mol} \%$ catalyst loading at $130{ }^{\circ} \mathrm{C}$. 


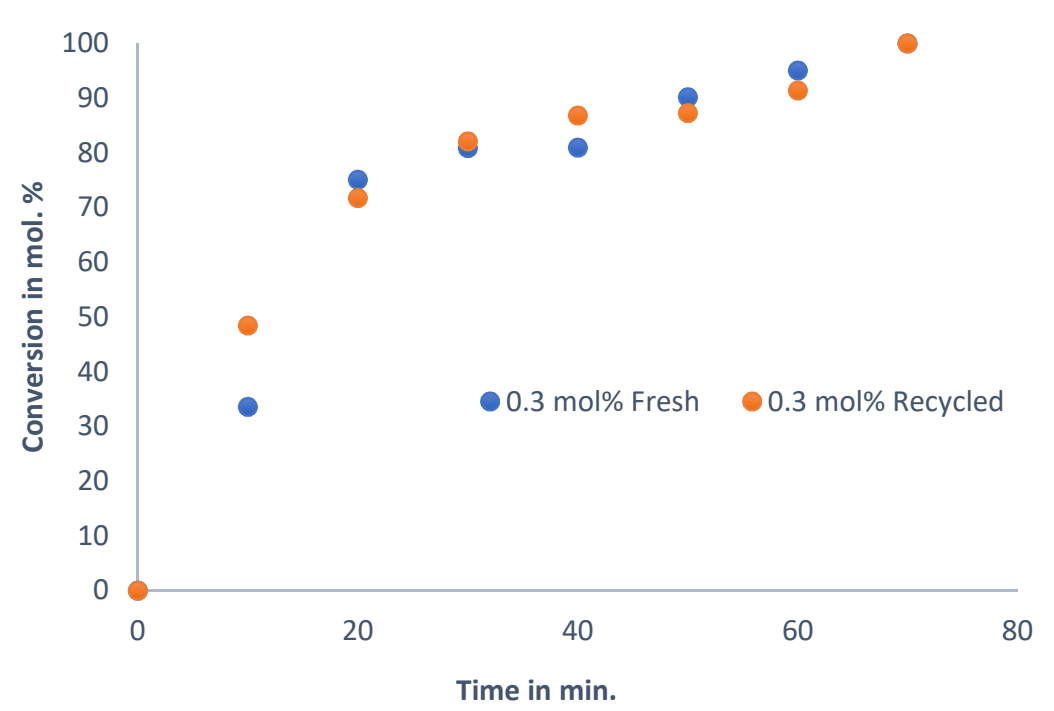

Figure 6. Reaction profile of fresh catalyst and recycled catalyst (4th cycle) at 10-min intervals.

The reaction profile of the fresh catalyst is the same as that of the recycled catalyst, even after four reaction cycles, characterised by a steep gradient for the first $20 \mathrm{~min}$, and then, as the reaction reaches completion, the reaction slows down, as a function of a decrease in reactant concentration. The deviation between the recycled catalysts and the fresh catalyst is small, and the catalyst maintains its activity even after the fourth reaction cycle. Therefore, the active species is still present in appreciable amounts, and any leaching that may occur is insignificant. In order to assess the quantity and activity of the leached Pd, leaching tests were initiated. The quantities of Pd that remained in solution at the end of the reaction are presented in Table 10. This shows the quantitative amounts of palladium that remained, as determined by ICP-OES analysis of the solutions, after each recycle, when the solid catalyst is centrifuged to separate the solid catalyst from the reaction medium.

Table 10. Moles of Pd in catalyst leached after each reaction cycle.

\begin{tabular}{ccc}
\hline Reaction & Moles of Pd in Solution $\times \mathbf{1 0}^{-\mathbf{6}}$ & \% Leached $\times \mathbf{1 0}^{-\mathbf{3}}$ \\
\hline R1 & 0.8660 & 1.2287 \\
R2 & 0.8024 & 1.1385 \\
R3 & 0.8244 & 1.1697 \\
\hline
\end{tabular}

R1 = First re-use of catalyst (2nd reaction).

The results show consistently low amounts of Pd leaching into the solution after every cycle. Various reports have cited a "release-and-capture" mechanism, where the active metal is released from its heterogeneous precursor into solution and can either perform catalysis as a $\mathrm{Pd}^{0}$ nanoparticle, or is abstracted as a soluble Pd species during oxidative addition. This is often referred to as leached Pd, which often remains in solution after the solid catalyst is removed. Some reports noted that the amount of active metal leached is a function of the iodobenzene present in the solution $[16,34,74-76]$, and once the reaction reaches completion and all iodobenzene is consumed, the active species gets deposited on the surface of the solid support or host material. In this case, a decrease of Pd in solution should be observed. Figure 7 shows the reaction profiles of the Hot Filtrate test and the Hg poisoning test, and the catalyst profile after quantitatively recycling the catalyst three times. Generally, for a catalyst to be deemed heterogeneous, the reaction has to cease with the removal of the solid catalyst. Hot filtration then monitors the reaction medium, from activation to completion, without the presence of the catalyst. Thus, the catalyst is allowed to react past its induction period, which was observed in Figure 5 i.e., after $10 \mathrm{~min}$ for a $0.3 \mathrm{~mol} \%$ loading, and then the catalyst is removed and the reaction medium monitored. If the removal of the solid catalyst stops the reaction, then the catalyst is completely heterogeneous. 
Additionally, $\mathrm{Hg}$ selectively poisons any $\mathrm{Pd}^{0}$ species in the reaction medium when the solid catalyst is removed after it has been activated. This helps determine the Pd species that is leached. If the addition of $\mathrm{Hg}$ stops the reaction, then the active species are $\mathrm{Pd}^{0}[5,16,34,65,74,75,77]$.

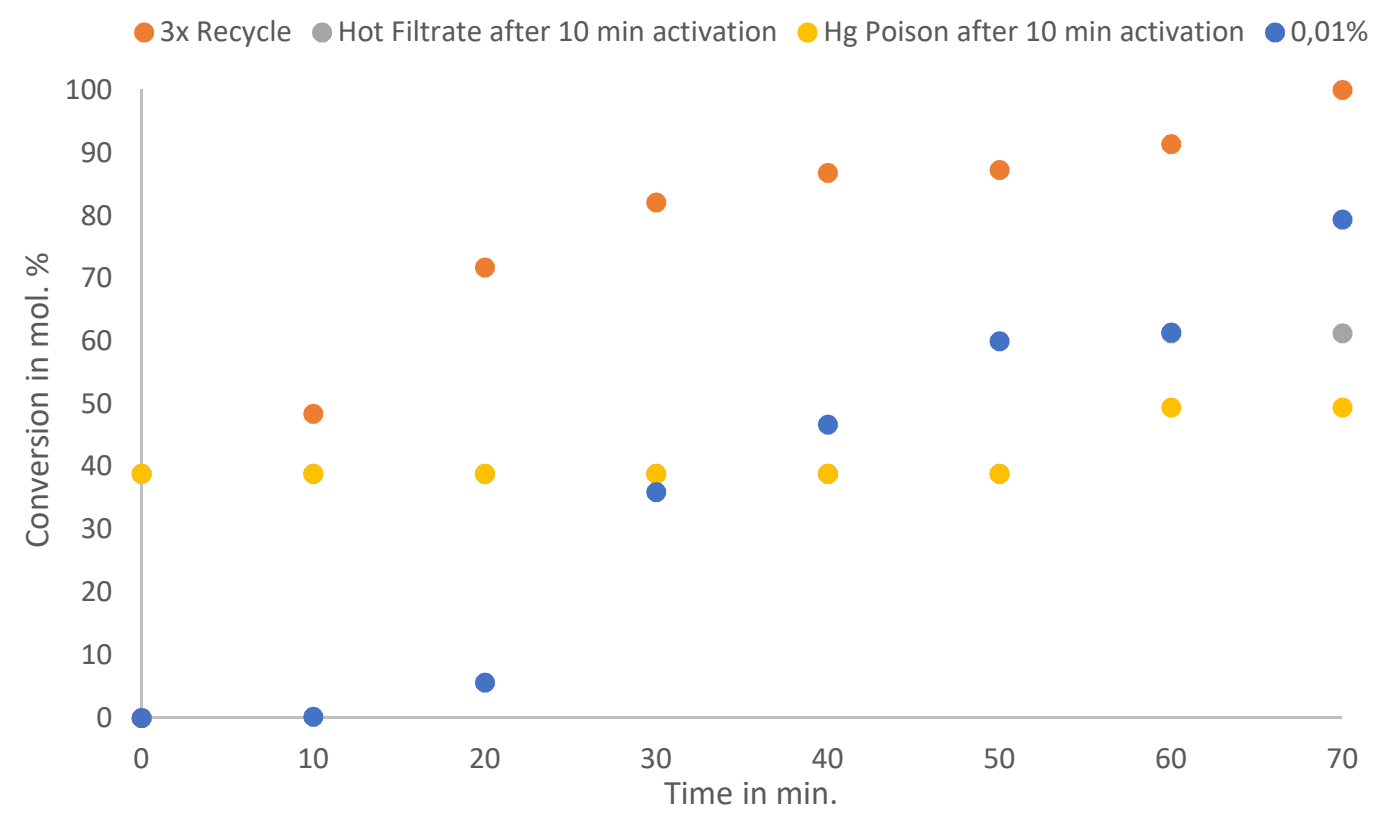

Figure 7. Reaction profile at 10-min intervals of the 3-times recycled catalyst, $0.01 \mathrm{~mol} \%$ catalyst, and hot reaction filtrate and $\mathrm{Hg} 0$-poisoned reaction filtrate.

Once the solid catalyst was removed after activation, the Hot Filtrate reaction still underwent an induction period $[65,76,78]$ lasting $30 \mathrm{~min}$, and thereafter conversion took place peaking at $70 \%$. The induction periods arise from the conversion of the catalyst material into the true catalyst prior to catalysis; thus the synthesised material acts as a host or pre-catalyst to improve the stability of the catalyst $[16,64,65]$. It is noteworthy that the leaching tests were performed after $40 \%$ conversion; however, an induction period was still needed, meaning that the leached species is not immediately active, requiring further activation into a molecular Pd species rather than being capable of surface chemistry, as in the case of leached nanoparticles. However, since the reaction continues after the solid material has been removed, a homogeneous component to the reaction can be inferred. The Hg0-poisoned filtrate exhibits the same general reaction profile as that in the Hot Filtrate reaction, with an equal induction period and gradual conversion. However, conversion for the $\mathrm{Hg} 0$-poisoned filtrate is lower than in the Hot Filtrate reaction, with a 50\% conversion after $70 \mathrm{~min}$. When the Hot Filtrate and the $\mathrm{Hg} 0$-poisoned reactions are allowed to reach completion, as shown in Figure 8, it is clear that these profiles match the reaction profiles of the fresh catalysts and recycled catalysts (Figures 5 and 6), only taking much longer to reach completion, that is, $14 \mathrm{~h}$ and $18 \mathrm{~h}$. 


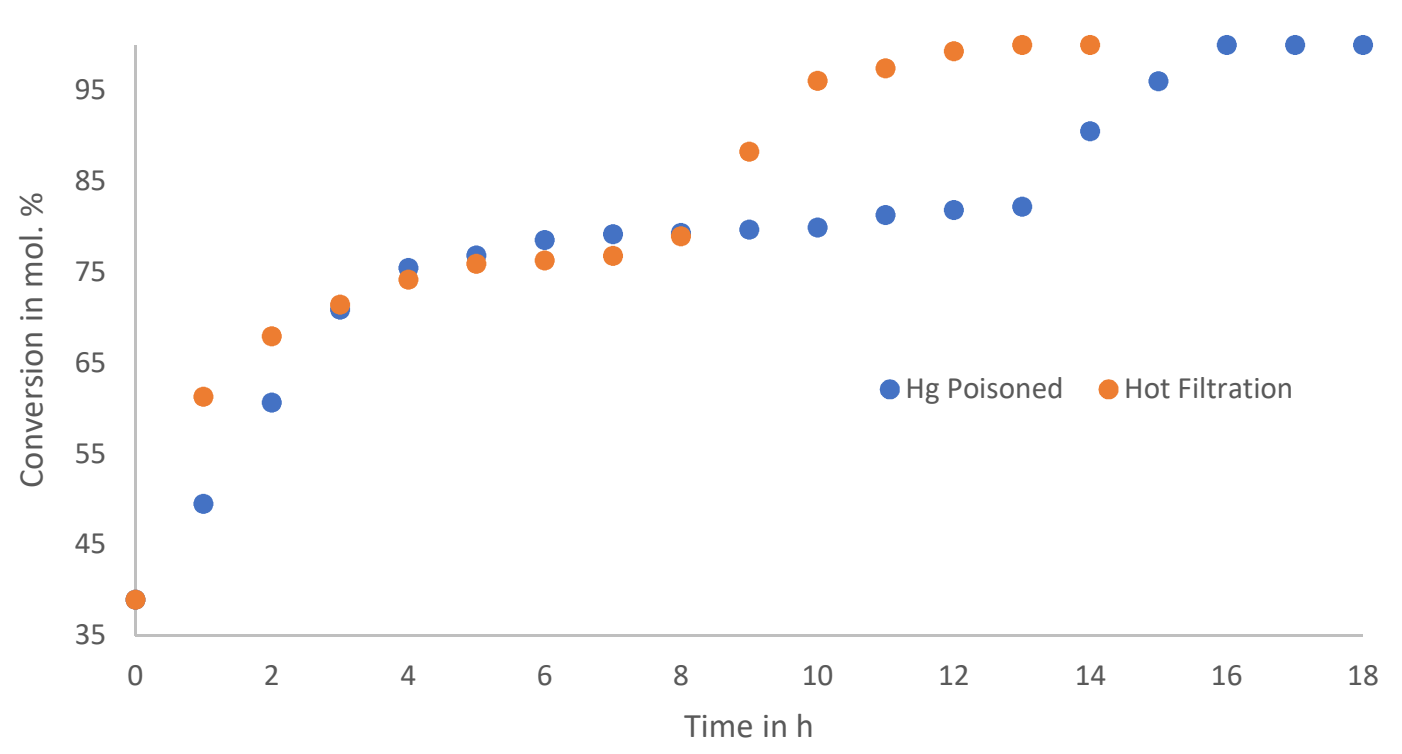

Figure 8. Hot reaction filtrate and $\mathrm{Hg}^{0}$-poisoned reaction filtrate to $100 \%$ conversion.

This result implies a rapid heterogeneous reaction from the solid catalyst, and a slower homogeneous reaction from the leached species, contributing to the overall reactivity of the catalyst.

\section{Materials and Methods}

\subsection{Synthesis of Catalyst Materials}

All the catalyst materials were synthesised using a method of solution combustion $[43,53,79,80]$.

\subsubsection{Synthesis Procedure for $\mathrm{Ce}_{0.89} \mathrm{Zr}_{0.03} \mathrm{Pd}_{0.08} \mathrm{O}_{2-\delta}$ Catalyst Material}

For example: $0.3550 \mathrm{~g}$ of palladium chloride (Sigma Aldrich, St. Louis, MO, USA) was dissolved in $4 \mathrm{~mL}$ of $\mathrm{HCl}$ ( $38 \%$, Alfa Aesar, Haverhill, MA, USA), forming chloropalladic acid $\left(\mathrm{H}_{2} \mathrm{PdCl}_{6}\right)$ and then dissolved in water. A separate solution of $9.5406 \mathrm{~g}$ of ammonium cerium nitrate (Sigma Aldrich, St. Louis, MO, USA) with $0.1387 \mathrm{~g}$ of zirconium oxynitrate (Sigma Aldrich, St. Louis, MO, USA) and $4.2407 \mathrm{~g}$ of urea in $40 \mathrm{~mL}$ of water was prepared and then added to the dissolved palladium solution while stirring on a hot plate at $100^{\circ} \mathrm{C}$. Once the volume had reduced to $\sim 10 \mathrm{~mL}$, the solution was placed into a preheated muffle furnace at $120^{\circ} \mathrm{C}$ to further evaporate water. After an hour, the temperature was increased to the ignition temperature of the fuel $\left(180^{\circ} \mathrm{C}\right)$ for one hour. The furnace was then ramped to $600{ }^{\circ} \mathrm{C}$ at a rate of $10^{\circ} \mathrm{C} / \mathrm{min}^{-1}$ and held at that temperature for $5 \mathrm{~h}$. The resultant catalyst, weighing $3.1566 \mathrm{~g}$, was then ground upon cooling with a mortar and pestle and characterised.

\subsubsection{Synthesis Procedure of $\mathrm{Ce}_{0.97} \mathrm{Zr}_{0.03} \mathrm{O}_{2-\delta}$ Catalyst Support Material}

The cerium-zirconium solid solution catalysts were synthesised by dissolving $10.6354 \mathrm{~g}$ ammonium cerium nitrate with $0.1391 \mathrm{~g}$ of zirconium oxynitrate and $4.7219 \mathrm{~g}$ of urea in $40 \mathrm{~mL}$ of water. Once the volume had reduced to $\sim 10 \mathrm{~mL}$ the solution was placed into a preheated muffle furnace at $120^{\circ} \mathrm{C}$ to further evaporate water. After an hour, the temperature was increased to the ignition temperature of the fuel $\left(180{ }^{\circ} \mathrm{C}\right)$ and held for one hour. The furnace was then ramped to $600^{\circ} \mathrm{C}$ at a rate of $10{ }^{\circ} \mathrm{C} / \mathrm{min}^{-1}$ and held at that temperature for $5 \mathrm{~h}$. The resultant catalyst, weighing $3.1264 \mathrm{~g}$, was then ground upon cooling with a mortar and pestle and characterised. 


\subsubsection{Synthesis Procedure of $\mathrm{Pd} / \mathrm{Ce}_{0.97} \mathrm{Zr}_{0.03} \mathrm{O}_{2-\delta}$ Material}

For the supported catalyst material, $0.2333 \mathrm{~g}$ of $\mathrm{PdCl}_{2}$ was dissolved in $\mathrm{HCl}$ and sonicated for five minutes. A solution of $2.0005 \mathrm{~g}$ of the $\mathrm{Ce}_{0.97} \mathrm{Zr}_{0.03} \mathrm{O}_{2-\delta}$ support material and $4.2654 \mathrm{~g}$ of urea in $40 \mathrm{~mL}$ of water was added to the dissolved $\mathrm{PdCl}_{2}$ solution while stirring on a hotplate at $100{ }^{\circ} \mathrm{C}$. Once the volume had reduced to $\sim 10 \mathrm{~mL}$, the solution was inserted into a preheated muffle furnace at $120^{\circ} \mathrm{C}$ to further evaporate water. After an hour, the temperature was increased to the ignition temperature of the fuel $\left(180^{\circ} \mathrm{C}\right)$ and held for one hour. The furnace was then ramped to $600^{\circ} \mathrm{C}$ at a rate of $10^{\circ} \mathrm{C} / \mathrm{min}^{-1}$ and held at that temperature for $5 \mathrm{~h}$. The resultant catalyst, weighing $2.2323 \mathrm{~g}$, was then ground upon cooling with a mortar and pestle and characterised.

\subsubsection{Activity Testing Procedure}

\section{Testing for Loading}

For the loading testing, catalysts of variable $\mathrm{mol} \%$ values were added to $3.4 \mathrm{mmol}$ of iodobenzene and $5.1 \mathrm{mmol}$ of olefin (1.5 mol equiv.), $6.8 \mathrm{mmol}$ of triethylamine (2 mol equiv.) and $2 \mathrm{~mL}$ of DMF in a $50-\mathrm{mL}$ pear-shaped flask and refluxed at $130{ }^{\circ} \mathrm{C}$. The progress of the reaction was monitored by Gas Chromatography with a Flame Ionisation dectector (GC-FID).

General Testing

An amount of $3.4 \mathrm{mmol}$ of aryl iodide and $5.1 \mathrm{mmol}$ of olefin (1.5 mol equiv.), $6.8 \mathrm{mmol}$ of triethylamine (2 mol equiv.), $2 \mathrm{~mL}$ of DMF and $7.5 \mathrm{mg}$ of catalyst $(0.3 \mathrm{~mol} \%)$ were added into a $50-\mathrm{mL}$ pear-shaped flask and refluxed at $130{ }^{\circ} \mathrm{C}$. The progress of the reaction was monitored via GC-FID.

\subsection{Leaching Tests}

The initial procedure for the leaching tests was the same as those described in the activity testing procedure, and deviations thereafter are noted in the various leaching tests procedures that follow.

\subsection{Quantitative Recyclability}

After the reaction, the solid catalyst was removed by centrifuging at $5000 \mathrm{rpms}$ for $30 \mathrm{~min}$ and the supernatant liquid was decanted to separate the catalyst. The catalyst was then dried and weighed once more for subsequent reactions. The procedure was repeated for three consecutive reactions monitored by GC-FID at every $10 \mathrm{~min}$ interval. To determine the amount leached in the filtrate, the filtrate was digested with $5 \mathrm{~mL}$ of concentrated $\mathrm{H}_{2} \mathrm{SO}_{4}$ and then diluted with double distilled water into a 10-mL volumetric flask for ICP-OES.

\subsection{Hot Filtrate}

After the activity testing procedure, the catalyst was filtered off while the reaction was hot, then reaction solution was allowed to react to completion. The reaction was monitored by GC-FID every $10 \mathrm{~min}$ interval for $70 \mathrm{~min}$ and then hourly until completion.

\subsection{Hg Poisoning}

After the activity testing procedure, the reaction solution was then reacted for $20 \mathrm{~min}$ to ensure activation and then the catalyst was removed as described in the quantitative reaction procedure. The supernatant liquid was then decanted into a clean 50-mL pear-shaped flask and fresh initial amounts of olefin, base and solvent, along with $1020 \mathrm{mmol}$ of mercury (300 mol equiv.), were added to the reaction solution. The reaction was monitored by GC-FID every $10 \mathrm{~min}$ interval for $70 \mathrm{~min}$ and then hourly until completion. 


\subsection{Instrumentation Details}

ICP-OES analysis was done on a Perkin Elmer (Waltham, MA, USA) 2100 Optima instrument and cerium, zirconium and palladium standards were purchased from CC Imelmann (South Africa). XRD analysis was carried out on a Bruker (Karlsruhe, Germany) D8 Advance instrument, fitted with a Bruker (Karlsruhe, Germany) VANTEC detector, with a $\mathrm{Cu} \mathrm{K} \alpha$ X-ray source at a voltage of $40 \mathrm{kV}$ and current of $40 \mathrm{~mA}$. Diffracplus XRD commander processing software was used. Microscopic analysis was carried out on a JOEL JEM 2100 instrument with a tungsten filament. HRTEM and STEM-EDS analyses were carried out with a JOEL (Akishima, Japan)-1010 electron microscope fitted with a tungsten filament for TEM analysis. The sample was then coated with gold and SEM was done on a Jeol (Akishima, Japan) JSM 6100 scanning electron microscope fitted with a Bruker signal processing unit detector. Reactions were monitored on a Perkin Elmer (Waltham, MA, USA) XL Autosystem with an FID detector.

\section{Conclusions}

Eight atomic percent of palladium and three atomic percent of zirconium were incorporated into a cerium host structure, to yield a $\mathrm{Ce} 0.89 \mathrm{Zr} 0.03 \mathrm{Pd} 0.08 \mathrm{O} 2-\delta$ material with a fluorite structure via solution combustion. The absence of a Pd-O shoulder in the [51] plane was indicative of complete incorporation of the $\mathrm{Pd}$, along with a lack of additional peaks from tetragonal zirconia, which was further evidence of complete Pd incorporation into the ceria structure, resulting in a single phase material. This incorporation resulted in changes in strain, crystallite size and interplanar spacing, due to the size of the atoms incorporated and electrostatic forces between them. The interplanar spacings from P-XRD corresponded to those found in the electron diffraction images of the spherical-shaped nanoparticles of the material. STEM-EDS line scans showed homogenous regions of ceria, zirconia and palladium, instead of localised regions of Pd surface deposits.

TOFs peaked at $1860 \mathrm{~h}^{-1}$ for the reaction between iodobenzene and methylacrylate, when DMF was used as a solvent and triethylamine was used as a base at $130{ }^{\circ} \mathrm{C}$. Polar aprotic solvents with coordinating ability were more effective with this material, in conjunction with triethylamine as the base. Electron-donating aryl halides were best suited for these reactions, while electron-donating aryl halides showed longer reaction times, since electron-deficient substrates strengthen the $C-X$ bond, supressing the oxidative addition of the material. Additionally, lower trans product yields were observed for electron-withdrawing aryl halides. Furthermore, para-activating substrates polarise the $\mathrm{C}-\mathrm{X}$ bond, making it susceptible to oxidative addition, thus resulting in a shorter reaction time. Electron-deficient olefins were best suited for the migratory insertion step, giving >99\% conversion over shorter reaction times, and steric hindrance about the double bond increases the reaction times. The catalyst was subjected to four consecutive reactions to $>99 \%$ conversion without a change in reaction time, with a consistent amount of $<1 \% \mathrm{Pd}$ leaching at the end of each reaction. The catalyst was found to be heterogeneous due to the lack of leaching. Additionally, Hot Filtration tests showed a slower-reacting homogenous component of the catalyst. The leached homogeneous material was found to be $\mathrm{Pd}^{2+}$, as the reaction continued after the addition of $\mathrm{Hg}^{0}$.

Author Contributions: Conceptualisation, Z.P.V. and H.B.F.; methodology, Z.P.V. and H.B.F.; validation, Z.P.V. and H.B.F.; formal analysis, Z.P.V.; investigation, Z.P.V.; resources, H.B.F.; data curation, Z.P.V. and H.B.F. writing: original draft preparation, Z.P.V.; writing: review and editing, H.B.F.; visualisation, Z.P.V. and H.B.F.; supervision, H.B.F.; project administration, H.B.F.; funding acquisition, H.B.F. All authors have read and agreed to the published version of the manuscript.

Funding: This research was funded by NRF grant number 118527.

Acknowledgments: The authors would like to acknowledge the contributions of the University of Kwa-Zulu Natal technical staff and well as the contribution of the Catalysis Research Group for their valid discussions of the work.

Conflicts of Interest: The authors declare no conflict of interest. 


\section{References}

1. Zhao, F.; Bhanage, B.M.; Shirai, M.; Arai, M. Heck Reactions of Iodobenzene and Methyl Acrylate with Conventional Supported Palladium Catalysts in the Presence of Organic and/and Inorganic Bases without Ligands. Chem. Eur. 2000, 6, 843-848. [CrossRef]

2. Torborg, C.; Beller, M. Recent Applications of Palladium-Catalyzed Coupling Reactions in the Pharmaceutical, Agrochemical, and Fine Chemical Industries. Adv. Synth. Catal. 2009, 351, 3027-3043. [CrossRef]

3. Schils, D.; Stappers, F.; Solberghe, G.; van Heck, R.; Coppens, M.; Van den Heuvel, D.; Van der Donck, P.; Callewaert, T.; Meeussen, F.; Bie, E.D.; et al. Ligandless Heck Coupling between a Halogenated Aniline and Acrylonitrile Catalyzed by Pd/C, Development and Optimization of an Industrial-Scale Heck Process for the Production of a Pharmaceutical Intermediate. Org. Process Res. Dev. 2008, 12, 530-536. [CrossRef]

4. Corbet, J.-P.; Mignani, G. Selected Patented Cross-Coupling Reaction Technologies. Chem. Rev. 2006, 106, 2651-2710. [CrossRef] [PubMed]

5. Islam, M.; Mondal, P.; Tuhina, K.; Roy, A.S. Heterogeneously catalyzed phosphine-free heck cross-coupling reaction of aryl halides with reusable palladium(II) schiff base complex. J. Braz. Chem. Soc. 2011, 22, 319-326. [CrossRef]

6. Biffis, A.; Zecca, M.; Basato, M. Palladium metal catalysts in Heck C-C coupling reactions. J. Mol. Catal. A Chem. 2001, 173, 249-274. [CrossRef]

7. Baumeister, P.; Meyer, W.; Oertle, K.; Seifert, G.; Steiner, H. Invention and Development of a Novel Catalytic Process for the Production of a Benzenesulfonic Acid-Building Block. Chimia 1997, 51, 144.

8. Kühl, O. Functionalised N-Heterocyclic Carbene Complexes; John Wiley \& Sons: Hoboken, NJ, USA, 2010.

9. Tao, F.; Hoefelmeyer, J.; Ostafin, A.; Yamashita, H. Metal Nanoparticles for Catalysis, Advances and Applications. R. Soc. Chem. 2014. [CrossRef]

10. Champion, Y.; Fecht, H.J.Ã. Nano-Architectured and Nanostructured Materials, Fabrication, Control and Properties; John Wiley \& Sons: Hoboken, NJ, USA, 2006.

11. Molnár, Á. Palladium-Catalyzed Coupling Reactions, Practical Aspects and Future Developments; John Wiley \& Sons: Hoboken, NJ, USA, 2013.

12. Gribble, G.W.; Gilchrist, T.L. Progress in Heterocyclic Chemistry, A Critical Review of the 2001 Literature Preceded by Two Chapters on Current Heterocyclic Topics, 1st ed.; Elsevier Science: Oxford, UK, 2002.

13. Gouadec, G.; Colomban, P. Raman Spectroscopy of Nanomaterials, How Spectra Relate to Disorder, Particle Size and Mechanical Properties. Prog. Cryst. Growth Charact. Mater. 2007, 53, 1-56. [CrossRef]

14. Mpungose, P.P.; Vundla, Z.P.; Maguire, G.E.; Friedrich, H.B. The Current Status of Heterogeneous Palladium Catalysed Heck and Suzuki Cross-Coupling Reactions. Molecules 2018, 23, 1676. [CrossRef]

15. Knowles, J.P.; Whiting, A. The Heck-Mizoroki cross-coupling reaction, a mechanistic perspective. Org. Biomol. Chem. 2007, 5, 31-44. [CrossRef] [PubMed]

16. Schmidt, A.F.; Kurokhtina, A.A. Distinguishing between the homogeneous and heterogeneous mechanisms of catalysis in the Mizoroki-Heck and Suzuki-Miyaura reactions, Problems and prospects. Kinet. Catal. 2012, 53, 714-730. [CrossRef]

17. Ji, Y.; Jain, S.; Davis, R.J. Investigation of Pd Leaching from Supported Pd Catalysts during the Heck Reaction. J. Phys. Chem. B 2005, 109, 17232-17238. [CrossRef]

18. Phan, N.T.; Van Der Sluys, M.; Jones, C.W. On the Nature of the Active Species in Palladium Catalyzed Mizoroki-Heck and Suzuki-Miyaura Couplings-Homogeneous or Heterogeneous Catalysis, A Critical Review. Adv. Synth. Catal. 2006, 348, 609-679. [CrossRef]

19. Molnár, Á. Efficient, Selective, and Recyclable Palladium Catalysts in Carbon-Carbon Coupling Reactions. Chem. Rev. 2011, 111, 2251-2320. [CrossRef] [PubMed]

20. Besson, M.; Gallezot, P. Deactivation of metal catalysts in liquid phase organic reactions. Catal. Today 2003, 81, 547-559. [CrossRef]

21. Redon, R.; GG Pena, N.; R Crescencio, F. Leaching in Metal Nanoparticle Catalysis. Recent Pat. Nanotech. 2014, 8, 31-51. [CrossRef]

22. Mpungose, P.P.; Sehloko, N.I.; Dasireddy, V.D.B.C.; Mahadevaiah, N.; Maguire, G.E.; Friedrich, H.B. Pd0.09Ce0.91O2- $\delta$ : A sustainable ionic solid-solution precatalyst for heterogeneous, ligand free Heck coupling reactions. Mol. Catal. 2017, 443, 60-68. [CrossRef] 
23. Perosa, A.; Tundo, P.; Selva, M.; Zinovyev, S.; Testa, A. Heck reaction catalyzed by Pd/C, in a t riphasic-organic/Aliquat 336/aqueous-solvent system. Org. Biomol. Chem. 2004, 2, 2249-2252. [CrossRef]

24. Biffis, A. Functionalised microgels, novel stabilisers for catalytically active metal colloids. J. Mol. Catal. A-Chem. 2001, 165, 303-307. [CrossRef]

25. Silberg, J.; Schareina, T.; Kempe, R.; Wurst, K.; Buchmeiser, M.R. N-Acyl-N,N-dipyridyl and $\mathrm{N}$-acyl-N-pyridyl-N-quinoyl amine based palladium complexes. Synthesis, $\mathrm{X}$-ray structures, heterogenization and use in Heck couplings. J. Organomet. Chem. 2001, 622, 6-18. [CrossRef]

26. Smith, G.S.; Mapolie, S.F. Iminopyridyl-palladium dendritic catalyst precursors, evaluation in Heck reactions. J. Mol. Catal. A-Chem. 2004, 213, 187-192. [CrossRef]

27. Liu, P.; Wang, L.; Yu, X. Chitosan-immobilized Palladium Complex, a Green and Highly Active Heterogeneous Catalyst for Heck Reaction. Chin. Chem. Lett. 2004, 15, 475-477.

28. Yang, H.; Zhang, G.; Hong, X.; Zhu, Y. Dicyano-functionalized MCM-41 anchored-palladium complexes as recoverable catalysts for Heck reaction. J. Mol. Catal. A Chem. 2004, 210, 143-148. [CrossRef]

29. Waghmode, S.; Girish Wagholikar, S.; Sivasanker, S. Heck Reaction over Pd-Loaded ETS10 Molecular Sieve. Chem. Soc. Jpn. 2003, 76, 1989-1992. [CrossRef]

30. Choudary, B.M.; Lakshmi Kantam, M.; Mahender Reddy, N.; Gupta, N.M. Layered-Double-Hydroxide-Supported Pd(TPPTS)2Cl 2 , A New Heterogeneous Catalyst for Heck Arylation of Olefins. Catal. Lett. 2002, 82, 79-83. [CrossRef]

31. Dams, M.; Drijkoningen, L.; De Vos, D.; Jacobs, P. Impact of Pd-mordenite pretreatment on the heterogeneity of Heck catalysis. Chem. Commun. 2002, 10, 1062-1063. [CrossRef]

32. Corma, A.; García, H.; Leyva, A.; Primo, A. Basic zeolites containing palladium as bifunctional heterogeneous catalysts for the Heck reaction. Appl. Catal. A Gen. 2003, 247, 41-49. [CrossRef]

33. Chanthateyanonth, R.; Alper, H. The first synthesis of stable palladium(II) PCP-type catalysts supported on silica-Application to the Heck reaction. J. Mol. Catal. A Chem. 2003, 201, 23-31. [CrossRef]

34. Zhao, F.; Murakami, K.; Shirai, M.; Arai, M. Recyclable Homogeneous/Heterogeneous Catalytic Systems for Heck Reaction through Reversible Transfer of Palladium Species between Solvent and Support. J. Catal. 2000, 194, 479-483. [CrossRef]

35. Wei, Y.; Jiao, J.; Zhang, X.; Jin, B.; Zhao, Z.; Xiong, J.; Li, Y.; Liu, J.; Li, J. Catalysts of self-assembled $\mathrm{Pt} @ \mathrm{CeO}_{2}$-delta-rich core-shell nanoparticles on 3D ordered macroporous $\mathrm{Ce}_{1-\mathrm{x}} \mathrm{Zr}_{\mathrm{x}} \mathrm{O}_{2}$ for soot oxidation, nanostructure-dependent catalytic activity. Nanoscale 2017, 9, 4558-4571. [CrossRef]

36. Varez, A.; Garcia-Gonzalez, E.; Sanz, J. Cation miscibility in $\mathrm{CeO}_{2}-\mathrm{ZrO}_{2}$ oxides with fluorite structure. A combined TEM, SAED and XRD Rietveld analysis. J. Mater. Chem. 2006, 16, 4249-4256. [CrossRef]

37. Deori, K.; Gupta, D.; Saha, B.; Awasthi, S.K.; Deka, S. Introducing nanocrystalline CeO2 as heterogeneous environmental friendly catalyst for the aerobic oxidation of para-xylene to terephthalic acid in water. J. Mater. Chem. A 2013, 1, 7091. [CrossRef]

38. Gulyaev, R.V.; Kardash, T.Y.; Malykhin, S.E.; Stonkus, O.A.; Ivanova, A.S.; Boronin, A.I. The local structure of $\mathrm{Pd}_{\mathrm{x}} \mathrm{Ce}_{1-\mathrm{x}} \mathrm{O}_{2-\delta}$ solid solutions. Phys. Chem. 2014, 16, 13523-13539.

39. Swartz, S.L. Catalysis by Ceria and Related Materials. J. Am. Chem. Soc. 2002, 124, 12923-12924. [CrossRef]

40. González-Cortés, S.L.; Imbert, F.E. Fundamentals, properties and applications of solid catalysts prepared by solution combustion synthesis (SCS). Appl. Gen. 2013, 452 (Suppl. C), 117-131. [CrossRef]

41. Snape, T.J. Recent advances in the semi-pinacol rearrangement of [small alpha]-hydroxy epoxides and related compounds. Chem. Soc. Rev. 2007, 36, 1823-1842. [CrossRef]

42. Kurian, M.; Kunjachan, C. Effect of lattice distortion on physical properties and surface morphology of nanoceria framework with incorporation of iron/zirconium. Nano-Struct. Nano-Objects 2015, 1, 15-23. [CrossRef]

43. Kim, T.; Vohs, J.M.; Gorte, R.J. Thermodynamic Investigation of the Redox Properties of Ceria-Zirconia Solid Solutions. Ind. Eng. Chem. 2006, 45, 5561-5565. [CrossRef]

44. Yuan, S.; Zhang, Q.; Xu, B.; Jin, Z.; Zhang, Y.; Yang, Y.; Zhang, M.; Ohno, T. Porous cerium dioxide hollow spheres and their photocatalytic performance. RSC. Adv. 2014, 4, 62255-62261. [CrossRef]

45. Andersson, C.M.; Andersson, M.; Borduas, N.; Borsini, E.; Broggini, G. Science of Synthesis: Cross Coupling and Heck-Type Reactions C-C Cross Coupling via C-H Activation; Thieme: New York, NY, USA, 2014.

46. Jagtap, S. Heck Reaction-State of the Art. Catalysts 2017, 7, 267. [CrossRef]

47. Oestreich, M. The Mizoroki-Heck Reaction; John Wiley \& Sons: Hoboken, NJ, USA, 2009. 
48. dos Santos, R.; Coriolano, M.; Godoi, R.; Monteiro, M.; De Oliveira, A.; Eberlin, H.N.; Neto, M.A.D. Phosphine-free Heck Reaction: Mechanistic Insights and Catalysis “On Water” Using a Charge-tagged Palladium Complex. New J. Chem. 2014, 38, 2958-2963. [CrossRef]

49. Trzeciak, A.M.; Ziółkowski, J.J. Structural and mechanistic studies of Pd-catalyzed CC bond formation: The case of carbonylation and Heck reaction. Coord. Chem. Rev. 2005, 249, 2308-2322. [CrossRef]

50. Ladd, M. Bonding, Structure and Solid-State Chemistry; Oxford University Press: Oxford, UK, 2016.

51. Bera, P.; Patil, K.C.; Jayaram, V.; Subbanna, G.N.; Hegde, M.S. Ionic Dispersion of Pt and Pd on $\mathrm{CeO}_{2}$ by Combustion Method, Effect of Metal-Ceria Interaction on Catalytic Activities for NO Reduction and CO and Hydrocarbon Oxidation. J. Catal. 2000, 196, 293-301. [CrossRef]

52. Hegde, M.S.; Madras, G.; Patil, K.C. Noble Metal Ionic Catalysts. Acc. Chem. Res. 2009, 42, 704-712. [CrossRef]

53. Deshpande, A.; Pinna, N.; Beato, P.; Antonietti, M.; Niederberger, M. Synthesis and Characterization of Stable and Crystalline $\mathrm{Ce}_{1-\mathrm{x}} \mathrm{Zr}_{\mathrm{x}} \mathrm{O}_{2-\delta}$ Nanoparticle Sols. Chem. Mater. 2004, 16, 2599-2604. [CrossRef]

54. Deshpande, P.A.; Hegde, M.S.; Madras, G. Pd and Pt ions as highly active sites for the water-gas shift reaction over combustion synthesized zirconia and zirconia-modified ceria. Appl. Catal. B Environ. 2010, 96, 83-93. [CrossRef]

55. Mae, Y. What the Darken-Gurry Plot Means About the Solubility of Elements in Metals. Metall. Mater. Trans. A 2016, 47, 6498-6506. [CrossRef]

56. Priya, N.S.; Somayaji, C.; Kanagaraj, S. Optimization of Ceria-Zirconia Solid Solution based on OSC Measurement by Cyclic Heating Process. Procedia Eng. 2013, 64 (Suppl. C), 1235-1241. [CrossRef]

57. Hernández, J.C.; Hungría, A.B.; Pérez-Omil, J.A.; Trasobares, S.; Bernal, S.; Midgley, P.A.; Alavi, A.; Calvino, J.J. Structural Surface Investigations of Cerium-Zirconium Mixed Oxide Nanocrystals with Enhanced Reducibility. J. Phys. Chem. C 2007, 111, 9001-9004. [CrossRef]

58. Crisp, T.G. Variations on a theme-recent developments on the mechanism of the Heck reaction and their implications for synthesis. Chem. Soc. Rev. 1998, 27, 427-436. [CrossRef]

59. Cabri, W.; Candiani, I. Recent Developments and New Perspectives in the Heck Reaction. Acc. Chem. Res. 1995, 28, 2-7. [CrossRef]

60. Heck, R.F. Palladium-catalyzed reactions of organic halides with olefins. Acc. Chem. Res. 1979, 12, $146-151$. [CrossRef]

61. Andersson, C.M.; Hallberg, A.; Daves, G.D. Regiochemistry of palladium-catalyzed arylation reactions of enol ethers. Electronic control of selection for .alpha.- or .beta.-arylation. J. Org. Chem. 1987, 52, 3529-3536. [CrossRef]

62. Tan, G.; Zhang, L.; Liao, X.; Shi, Y.; Wu, Y.; Yang, Y.; You, J. Copper- or Nickel-Enabled Oxidative Cross-Coupling of Unreactive $\mathrm{C}\left(\mathrm{sp}^{3}\right)-\mathrm{H}$ Bonds with Azole $\mathrm{C}\left(\mathrm{sp}^{2}\right)-\mathrm{H}$ Bonds, Rapid Access to $\beta$-Azolyl Propanoic Acid Derivatives. Org. Lett. 2017, 19, 4830-4833. [CrossRef] [PubMed]

63. Petrucci, C.; Cappelletti, M.; Piermatti, O.; Nocchetti, M.; Pica, M.; Pizzo, F.; Vaccaro, L. Immobilized palladium nanoparticles on potassium zirconium phosphate as an efficient recoverable heterogeneous catalyst for a clean Heck reaction in flow. J. Mol. Catal. A Chem. 2015, 401 (Suppl. C), 27-34. [CrossRef]

64. Weck, M.; Jones, C.W. Mizoroki-Heck Coupling Using Immobilized Molecular Precatalysts, Leaching Active Species from Pd Pincers, Entrapped Pd Salts, and Pd NHC Complexes. Inorg. Chem. 2007, 46, 1865-1875. [CrossRef]

65. Amoroso, F.; Colussi, S.; Del Zotto, A.; Llorca, J.; Trovarelli, A. PdO hydrate as an efficient and recyclable catalyst for the Suzuki-Miyaura reaction in water/ethanol at room temperature. Catal. Commun. 2011, 12, 563-567. [CrossRef]

66. Salem, R. Heck Coupling Styrene with Aryl halides Catalyzed by Palladium Complexes in Biphasic Media. J. Société Chim. Tunis. 2009, 11, 59-67.

67. Jung, I.G.; Son, S.U.; Park, K.H.; Chung, K.-C.; Lee, J.W.; Chung, Y.K. Synthesis of Novel Pd-NCN Pincer Complexes Having Additional Nitrogen Coordination Sites and Their Application as Catalysts for the Heck Reaction. Organometallics 2003, 22, 4715-4720. [CrossRef]

68. Limberger, J.; Poersch, S.; Monteiro, A. Pd-Catalyzed Heck Reactions of Aryl Bromides with 1,2-Diarylethenes. J. Braz. Chem. Soc. 2011, 22, 1389-1394. [CrossRef] 
69. Jana, R.; Pathak, T.P.; Sigman, M.S. Advances in Transition Metal (Pd,Ni,Fe)-Catalyzed Cross-Coupling Reactions Using Alkyl-organometallics as Reaction Partners. Chem. Rev. 2011, 111, 1417-1492. [CrossRef] [PubMed]

70. Augustine, R.L.; O'Leary, S.T. Heterogeneous catalysis in organic chemistry Part 8 The use of supported palladium catalysts for the Heck arylation. J. Mol. Catal. A Chem. 1992, 2, 229-242. [CrossRef]

71. Hallberg, A.; Westfelt, L.; Holm, B. Palladium-catalyzed arylation of methyl vinyl ether. J. Org. Chem. 1981, 26, 5414-5415. [CrossRef]

72. Du, Z.; Zhou, W.; Bai, L.; Wang, F.; Wang, J.X. In Situ Generation of Palladium Nanoparticles, Reusable, Ligand-Free Heck Reaction in PEG-400 Assisted by Focused Microwave Irradiation. Angew. Chem. Int. Ed. Engl. 2011, 42, 1881-1882. [CrossRef]

73. Bumagin, N.A.; More, P.G.; Beletskaya, I.P. Synthesis of substituted cinnamic acids and cinnamonitriles via palladium catalyzed coupling reactions of aryl halides with acrylic acid and acrylonitrile in aqueous media. J. Organomet. Chem. 1989, 371, 397-401. [CrossRef]

74. Heidenreich, R.G.; Krauter, J.G.E.; Pietsch, J.; Köhler, K. Control of Pd leaching in Heck reactions of bromoarenes catalyzed by Pd supported on activated carbon. J. Mol. Catal. A Chem. 2002, 182-183 (Suppl. C), 499-509. [CrossRef]

75. Biffis, A.; Zecca, M.; Basato, M. Metallic Palladium in the Heck Reaction, Active Catalyst or Convenient Precursor? Eur. J. Inorg. Chem. 2001, 2001, 1131-1133. [CrossRef]

76. Del Zotto, A.; Colussi, S.; Trovarelli, A. Pd/REOs catalysts applied to the Suzuki-Miyaura coupling. A comparison of their catalytic performance and reusability. Inorg. Chimica Acta 2018, 470 (Suppl. C), $275-283$. [CrossRef]

77. Richardson, J.M.; Jones, C.W. Poly(4-vinylpyridine) and Quadrapure TU as Selective Poisons for Soluble Catalytic Species in Palladium-Catalyzed Coupling Reactions-Application to Leaching from Polymer-Entrapped Palladium. Adv. Syn. Catal. 2006, 348, 1207-1216. [CrossRef]

78. Del Zotto, A.; Zuccaccia, D. Metallic palladium, PdO, and palladium supported on metal oxides for the Suzuki-Miyaura cross-coupling reaction, a unified view of the process of formation of the catalytically active species in solution. Catal. Sci. 2017, 7, 3934-3951. [CrossRef]

79. Shah, P.R.; Kim, T.; Fornasiero, P.; Gorte, R.J. Evidence for Entropy Effects in the Reduction of Ceria-Zirconia Solutions. Chem. Mater. 2006, 18, 5363-5369. [CrossRef]

80. Varma, A.; Mukasyan, A.S.; Rogachev, A.S.; Manukyan, K.V. Solution Combustion Synthesis of Nanoscale Materials. Chem. Rev. 2016, 116, 14493-14586. [CrossRef] 